\title{
Article \\ Effect of Rotating Magnetic Field on Microstructure in AlCuSi Alloys
}

\author{
Piotr Mikolajczak (1)
}

check for

updates

Citation: Mikolajczak, P. Effect of Rotating Magnetic Field on Microstructure in AlCuSi Alloys. Metals 2021, 11, 1804. https:// doi.org/10.3390/met11111804

Academic Editor: Frank Czerwinski

Received: 16 September 2021

Accepted: 5 November 2021

Published: 9 November 2021

Publisher's Note: MDPI stays neutral with regard to jurisdictional claims in published maps and institutional affiliations.

Copyright: (C) 2021 by the author. Licensee MDPI, Basel, Switzerland. This article is an open access article distributed under the terms and conditions of the Creative Commons Attribution (CC BY) license (https:/ / creativecommons.org/licenses/by/ $4.0 /)$.
Institute of Materials Technology, Poznan University of Technology, Piotrowo 3, 60-965 Poznan, Poland; Piotr.Mikolajczak@put.poznan.pl; Tel.: +48-(61)-665-2804

\begin{abstract}
The solidification of AlCuSi alloys with Mn and Fe was studied by rotating a magnetic field to understand the effect of melt flow. The specimens solidified with a forced convection, low cooling rate and low temperature gradient. Electromagnetic stirring generated by an electric coil around the specimens caused a transformation from equiaxed dendritic to rosette morphology, occasionally with spheroids and minor dendrites. The transformation was quantitatively observed with a specific surface $S_{v}$, that decreased for almost all alloys and marked the flow effect on $\alpha-A l$. The computer coupling of phase diagrams and thermochemistry (CALPHAD) technique was applied for the calculation of phase diagrams and property diagrams. Forced convection decreased secondary dendrite arm spacing $\lambda_{2}$ in almost all alloys, while it increased slightly in one studied alloy. The length of detrimental $\beta-\mathrm{Al}_{5} \mathrm{FeSi}$ phases decreased in the alloy, where $\beta$ starts to precipitate in the presence of $\alpha-\mathrm{Al}$, while increasing in alloys where $\beta$ starts as first and grows in the fully liquid melt. The average overall dimension of the Mn-rich phases increased in almost all alloys, and the number density decreased under flow. The modification of spacing for AlSi-eutectics and $\mathrm{Al}_{2} \mathrm{Cu}$ was analyzed. It was found that the occurrence of $\mathrm{Al}_{2} \mathrm{Cu}$ does not influence the fluid flow and vice versa.
\end{abstract}

Keywords: electromagnetic stirring; aluminum alloys; solidification; dendrite arm spacing; rosettes; $\mathrm{Al}_{2} \mathrm{Cu}$ phases

\section{Introduction}

The unique combination of properties provided by aluminum alloys make it one of the most economical and universal, and thus attractive, metallic materials for a broad range of uses, from soft foil to the most advanced engineering applications [1]. Generally, aluminum alloys (e.g., A319 or EN AC-45000), are second only to steels in use as structural metals. The increasing demand for such material properties as high electrical and thermal conductivities, non-toxicity, non-sparking and non-magnetic behavior, alloys' surface appearance, high corrosion resistance, and especially high strength-to-weight ratio and ductility, has indicated the need for the precise control of composition, heat treatment, and microstructure through precise production practices $[2,3]$.

During the dendritic solidification of a casting, a number of processes take place simultaneously within the semisolid region; crystallization, solute redistribution, ripening, inter-dendritic fluid flow and solid movement. Flemings [4] discovered a non-dendritic structure in the semi-solid state of metallic alloys with special rheological properties. In the presence of intensive melt stirring, non-dendritic structures may occur, with the primary $\alpha-\mathrm{Al}$ phase shaped as spheroids (globular) or rosettes [5]. Non-dendritic structures exhibit rheological properties [6] improving the mechanical properties of alloys [7] and composites [8], making semisolid metal processing (SSM) [9], thixoforming [10], rheocasting [11] and thixowelding [12] unique for the production of advanced engineering parts [13]. Semisolid slurries [14] with globular solid particles may be produced by magnetohydrodynamic (MHD) [15] or mechanical stirring [16]. Forced convection induced by rotating magnetic fields (RMF), also labeled as electromagnetic stirring (EMS) [17,18], can transform the microstructure [19] and improve the properties of billets and castings [20]. 
Cast aluminum alloys contain mainly $\mathrm{Si}, \mathrm{Cu}$, and $\mathrm{Mg}$ as the major alloying elements [1]. Copper, for example, is added to $\mathrm{Al}$ primarily to increase strength [21]. Increasing the $\mathrm{Cu}$ content causes a continuous increase in the hardness [22]; however, the strength and especially the ductility depend on how the $\mathrm{Cu}$ element is distributed [23]. In AlCuSi aluminum-based alloys, the presence of $\mathrm{Cu}$ causes formation of binary $\left(\alpha-\mathrm{Al}+\mathrm{Al}_{2} \mathrm{Cu}\right)$ and ternary eutectic $\left(\alpha-\mathrm{Al}+\mathrm{Al}_{2} \mathrm{Cu}+\beta-\mathrm{Si}\right)$.

The main impurities that exist in recycled $\mathrm{Al}-\mathrm{Si}$ foundry alloys are iron $(\mathrm{Fe})$, manganese $(\mathrm{Mn})$, copper $(\mathrm{Cu})$, and zinc $(\mathrm{Zn})$. The application of recycled aluminum causes the formation of rich intermetallics in iron, even by small amounts of low soluble iron (in Al max. $0.05 \%$ ). The earliest optical studies have reported a range of particles divided into: polyhedral crystals, Chinese script and thin needles [24]. Brittle and hard $\beta-\mathrm{Al}_{5} \mathrm{FeSi}$ platelets and needles have a detrimental effect on alloy properties, especially the ductility of the material [25].

Thus, alloying elements such as $\mathrm{Mn}, \mathrm{Cr}$, Mo and Be have been used to replace the acicular $\beta$-phases, with precipitates that have the granular or skeleton morphology. In the presence of iron and $\beta-\mathrm{Al}_{5} \mathrm{FeSi}$ platelets, the most common alloying addition is manganese, which has the possibility of transforming needle-like Fe phases to blocky ones.

Following research on non-dendritic structures produced by forced convection during solidification or remelting, the development of $\mathrm{Cu}$ containing aluminum alloys and the problematic presence of iron, all need more systematic examination. In this paper, according to common industrial aluminum alloys, A319 and EN AC-45000, with composition: 5-7 wt.\% Si, 3-5 wt.\% Cu, 1 wt. \% Fe, 0.2-0.65 wt.\% Mn and Al balanced, several alloys with close compositions (AlCu4Si6) were studied.

Here, the effect of forced convection on specimens solidifying with equiaxed microstructure has been studied as a function of chemical composition $(\mathrm{Cu}, \mathrm{Si}, \mathrm{Fe}$, and $\mathrm{Mn}$ content) based on $\mathrm{Al}-4 \mathrm{wt} . \% \mathrm{Cu}$ and $\mathrm{Al}-10 \mathrm{wt} . \% \mathrm{Cu}$ alloys. The specimens were solidified during slow cooling in controlled thermal conditions, without or with an induced rotating magnetic field (RMF). Microstructural examination was carried out, with measurements taken using the Fiji software via optical metallography. In order to determine the sequence of growth of individual precipitating phases, the ternary phase diagram and property diagrams were calculated using the Thermo-Calc [26] software (Thermo-Calc Software, Stockholm, Sweden).

The non-dendritic microstructures are mostly explained by dendrite fragmentation in the presence of melt flow [4]. As has been mentioned by Flemings [4], the mechanism responsible for fragmentation may be: (a) remelting of the dendrite root; (b) dendrite arm fracture; (c) recrystallization caused by the forced flow inducing mechanical stress; or (d) a combination thereof.

\subsection{Rosettes}

Solidification of the AlCu10 alloy by forced convection [27] led to a microstructure with many round crystals shaped as clusters. With the help of classical light optical microscope and in 3D visualization, Niroumand and Xia [27] observed that, on a 2D micrograph, globular crystals appeared to be separate. The authors then found that globular crystals of clusters are connected to each other in the 3D geometry, and argued that dendrite fragmentation and the resulting agglomeration controlled the microstructure formation only weakly. In conclusion, the authors suggested that rosette-shaped clusters constitute the ripened arms of deformed dendritic crystals. Experiments with liquid alloys [28] moving along a cooled plate, have proved that during flow, crystals have the ability to grow as agglomerates because of collisions with each other and they may also coalesce. Therefore, it is possible to observe $\alpha$-Al crystals in the resultant microstructure, in the form of rosettes, fully shaped dendrites, and some globular grains. The cellular automaton method applied for analysis of the rosette morphology and its growth [29], proved that melt flow induces rotation of the dendrite tip caused by solutal and thermal advection. The dimension of the crystal was prescribed by the size of the bending parameter, and, 
ultimately, such a rosette might precipitate without external mechanical interaction coming from forced convection.

\subsection{Spheroids}

Theoretical study on solidification under forced flow was demonstrated in [30], with the focus on the stability of the liquid-solid interface. Computer analysis demonstrated that, when turbulence and shear rate increase significantly, the growth morphology may transform from an equiaxed dendrite to a spheroid via the rosette. Numerical analysis using the Monte Carlo method [31] proved that a tendency for dendritic growth was diminished and globularization of the particle was caused by rotation of the primary solid phase and removal of constitutional undercooling at the solid-liquid interface, through limitation of the thermal and solutal diffusion layers.

Ji et al. [30] conducted experiments on rheomoulding by high shear rates, obtaining a spherical morphology, instead of a dendrite or rosette. In the study by [32], the globular structure was produced using internal cooling and intensive stirring, and it was found that forced convection caused the uniform chemical composition near the solid-liquid interface. The idea that a nondendritic microstructure results from the globular growth and natural nucleation was supported by experiments on succinonitrile (SCN)-5\% water [33]. Intensive stirring leading to the growth in spheroidal forms just below the liquidus temperature was also proven in the study on the AlCu4.5 alloy [34].

\subsection{Dendrites}

In directional solidification, the microstructure is characterized by secondary dendrite arm spacing $\lambda_{2}$ and by primary dendrite arm spacing $\lambda_{1}$ [35-38]. For equiaxed grain morphologies resulting from free growth by equiaxed solidification, metallurgists traditionally measure grain size and secondary dendrite arm spacing $\lambda_{2}$, the distance between grains, or the number of grains [35]. Voorhees et al. [39] proposed and applied an additional measure of specific surface $S_{v}$ of dendrites.

Secondary dendrite arms first start to form as perturbations located close to the dendrite tip, they then develop into cell-like structures and finally form independent arms located in parallel to each other. These arms grow with similar sizes, which can vary during ripening. Growth through solutal fluctuations and natural thermal convection leads to arms of various sizes where the larger arms overgrow smaller dissolving arms. The coarsening occurring during solidification, determines the distance between secondary arms $\lambda_{2}[40,41]$. The concept that dendrite coarsening is diffusion controlled, has led to the formulation of many mathematical models $[37,42,43]$, where secondary dendrite arm spacing $\lambda_{2}$, is simply calculated as a function of the local solidification time $t$ :

$$
\lambda_{2}=\mathrm{c}_{1} \cdot \mathrm{t}^{\mathrm{n} 1}
$$

where $\mathrm{n}_{1}=0.48$ for convective regime and 0.33 for diffusive mass transport [44]. The material constants (concentration and diffusion coefficient, etc.) are included in $c_{1}$ coefficient given in different forms by Mortensen [45], Kattamis and Flemings [42], and Voorhees and Glicksman [46]. Based on the local cooling rate, Bouchard and Kirkaldy [37,47] proposed the following expression:

$$
\lambda_{2}=\mathrm{c}_{2} \cdot \mathrm{R}^{-\mathrm{n} 2}
$$

where $c_{2}=$ coefficient and $\mathrm{n}_{2}$ is in the range between 0.22 and 0.33 for AlSi alloys [47] that have various $\mathrm{Si}$ contents, or, more generally, $\mathrm{n}_{2}=0.33$ [37]. Beside the mathematical models, many numerical models have been developed and simulations have been carried out $[38,48]$.

Mullis [49] found that melt flux from the root of the secondary arm towards the tip will reduce the ripening rate, while flow in the opposite direction will enhance the ripening rate. For convection aligned along the primary dendrite root, a transverse flow will be aligned along secondary trunks and will enhance the ripening. The melt flow effect on 
secondary dendrite arm spacing $\lambda_{2}$ could be insignificant (an increase in the ripening rate), because of the four-fold symmetry of the dendritic grain.

Because of the flow increase caused by coarsening, for the flow-governed dendrite ripening, in a model for Ostwald ripening proposed by Diepers et al. [50], where secondary spacing $\lambda_{2}$ depends on solidification time, the exponent $n_{1}$ changed to 0.5 instead of 0.33 for diffusive ripening. The simulation results are in line with experimental results obtained by Steinbach and Ratke [44] on directional solidification of AlSi7Mg0.6 alloy (A357) and the findings of Kasperovich [51], Ratke and Thieringer [52] on the convective ripening theory. Steinbach and Ratke [44] found that with increasing convection velocities (e.g., by $\mathrm{t}=1250 \mathrm{~s}$ from $80 \mu \mathrm{m}$ to $140 \mu \mathrm{m}$ ), caused by increasing electromagnetic induction, secondary dendrite spacing $\lambda_{2}$ increases continually. According to the value of the $c_{1}$ coefficient from [44] applied in power law expressions of solidification time, the exponent $\mathrm{n}_{1}$ (in Equation (1)) takes value 0.48 by flow caused by magnetic stirring $(6 \mathrm{mT})$, instead of 0.36 in a solute-controlled system with gravity induced flow.

Measuring the secondary dendrite arm spacing $\lambda_{2}$, for the dendritic structure characterization, does not describe the complexity of the dendritic structure, even when complemented by primary stem spacing $\lambda_{2}$ and grain size. Marsh and Glicksman [53] found that, the specific interfacial area $S_{v}$ was proportional to the solidification time $t$, despite the severe morphological changes from dendritic to spheroidal structure induced by the coarsening processes, and described this relationship as:

$$
\mathrm{S}_{\mathrm{V}} \sim \mathrm{t}^{-1 / 3}
$$

Loué and Suéry [54] introduced a dimensionless grain-specific shape factor, which is the square of the average solid-liquid interface area per grain, complemented by two factors, i.e., factor of number of grains per unit area and calibration factor for the attainment of value 1 by perfectly spherical solid phase grains.

\subsection{Eutectics}

The first classification of eutectics $[35,36]$ is based on their growth mechanism and includes the cooperative growth where two (or more) phases grow together as a diffusion couple, and the divorced growth, where there is no exchange of solute between the two solid phases [37]. During the solidification of two-phase (or more) eutectic alloys, two (or more) solutes are rejected, and accumulate in front of the solid phase. The accumulation and exchange of solute between simultaneous phases occurs in the liquid phase, and this may be greatly influenced by forced flow. Jackson and Hunt $[36,55]$ determined the eutectic spacing $\lambda_{\mathrm{E}}$ as:

$$
\lambda_{\mathrm{E}}=\mathrm{c}_{3} \cdot \mathrm{V}^{-0.5}
$$

where $\mathrm{V}=$ solidification front velocity and $\mathrm{c}_{3}=$ coefficient.

In the directional solidification of the AlSi7Mg0.6 alloy [44], forced convection reduced $\lambda_{E}$ with increasing solidification velocity according to the well-known Jackson and Hunt relationship (4) and also increased eutectic spacing, e.g., for the solidification velocity of $90 \mu \mathrm{m} / \mathrm{s}$ from 3 to $7 \mu \mathrm{m}$. In accordance with earlier results obtained by Sous [56], directional solidification of AlSi5/7/9Fe0.2/0.5/1.0 alloys [57] did not present any clear coincidence of the eutectic spacing with melt flow.

Eutectic solidification, for e.g., AlSi5Fe1.0 [58], occurs at the final eutectic reaction at $575{ }^{\circ} \mathrm{C}$. In directional solidification [58] at, for e.g., a temperature gradient of $3 \mathrm{~K} / \mathrm{mm}$, the mushy zone is about $18 \mathrm{~mm}$ wide, whilst the eutectic zone is about $1-3 \mathrm{~mm}$ wide and the deep flow between dendrites might be reduced. However, in the case of the equiaxed solidification [59] at a temperature gradient of $0.143-0.214 \mathrm{~K} / \mathrm{mm}$ and a cooling rate of $0.112-0.626 \mathrm{~K} / \mathrm{s}$, equiaxed dendrites moving in the liquid with similarly growing eutectic phases grew freely in the mush, and one cannot expect that convection is diminished by dendrites. In the current equiaxed solidification at a temperature gradient of $G_{\text {liq- }-470}=0.132(\mathrm{~K} / \mathrm{mm})$ and cooling rate of $R_{\text {liq-sol }}=0.103(\mathrm{~K} / \mathrm{s})$, equiaxed dendrites 
moving in the liquid with similarly growing eutectic phases grew freely in the mush zone, and, similarly, one cannot expect that convection is diminished by the dendrites.

\subsection{Intermetallics}

The presence of Fe-rich intermetallic phases and its shortening under forced flow was observed in [60], where for specimens solidified in a copper mold, stirring decreased the average length in the range of $\mathrm{L}_{\beta}=4.5-5 \mu \mathrm{m}$, and in a sand mold, the average length decreased under flow from $L_{\beta}=9-10 \mu \mathrm{m}$ to $7-8 \mu \mathrm{m}$. Fang et al. [61] found that for the LM24 alloy (AlSi8Cu3Fe1.3), $\beta-\mathrm{Al}_{5} \mathrm{FeSi}$ with lengths $95-110 \mu \mathrm{m}$ were completely eliminated, and for the LM25 alloy (AlSi7Mg0.2-0.6Fe0.5), the forced flow caused a shortening of $\beta$ phases from 75 to $15 \mu \mathrm{m}$. Steinbach et al. [62] observed the growth of about $280 \mu \mathrm{m}$ long Fe platelets in the eutectic center formed by stirring in the directionally solidified AlSi7Fe1.0 alloy, while the same system without forced convection generated shorter $\beta$ phases, about $160 \mu \mathrm{m}$ long. In the directional solidification of $\mathrm{AlSi} 5 / 7 / 9 \mathrm{Fe} 0.2 / 0.5 / 1.0$ alloys [31], the electromagnetic stirring caused an approximately $20 \%$ shortening of $\beta$ platelets in the outer dendritic region of the specimen with a diameter of $8 \mathrm{~mm}$, and a $9 \%$ increase in the eutectic center. The histograms demonstrated that $\beta$ needles with lengths between 5 and $40 \mu \mathrm{m}$, are the most common, and a lower average length $\mathrm{L}_{\beta}$ of all inspected precipitates was due to higher number density of small phases.

Nafisi [60] proved an increase under stirring in the number density for the copper mold from $\mathrm{n}_{\beta}=5000-13000 \mathrm{~mm}^{-2}$ to $\mathrm{n}_{\beta}=5000-14,000 \mathrm{~mm}^{-2}$, and the sand mold from $\mathrm{n}_{\beta}=600-1200 \mathrm{~mm}^{-2}$ to $\mathrm{n}_{\beta}=800-2600 \mathrm{~mm}^{-2}$, for the AlSi6.8Fe0.8 alloy. Mikolajczak and Ratke [63], in directional solidification, showed an increase in number density $\mathrm{n}_{\beta}$, in the eutectic rich center $(42 \%)$ and in the outer part $(17 \%)$ of $8 \mathrm{~mm}$ diameter specimens.

In the current paper, the effect of forced convection on specimens solidifying with an equiaxed microstructure has been studied as a function of chemical composition by microstructural examination with measurements of the occurring phases and calculated [26] growth sequence of individual precipitating phases.

\section{Materials and Methods}

The study investigated nine aluminum alloys (AlCu4, AlCu4Si6, AlCu4Si6Fe1, AlCu4Si6Mn0.65, AlCu4Si6Fe1Mn0.65, AlCu10Si10, AlCu10Si10Fe1, AlCu4Si6Fe2 and AlCu4Si6Mn2) which were prepared from pure components: Al (99.999\% HMW Hauner GmbH \& Co. KG, Röttenbach, Germany), Cu (99.999\% HMW Hauner), Si (99.9999\% NewMet House, Essex, UK), Mn (99.98\% NewMet House), and Fe (99.99+\% HMW Hauner). The alloy was melted ( $\mathrm{min} .1 .5 \mathrm{~h}$ ) in a resistance furnace using a graphite crucible $(50 \mathrm{~mm}$ diameter) without addition of the modifier. The melt was degassed with argon and, from the beginning of the melting process, a continuous flux of argon was used to flush the crucible.

The cylindrical specimens ( $65 \mathrm{~mm}$ in height and $38 \mathrm{~mm}$ in diameter) were heated, melted and solidified in a graphite crucible. Both the alloy and the crucible were heated to a temperature of $800-805{ }^{\circ} \mathrm{C}$ and moved from the electric resistance furnace into the solidification facility provided with thermal insulation (Sibral Fiberfrax, Unifrax, Tonawanda, NY, USA) and electric coils. The temperature was measured: (1) in the crucible, $3 \mathrm{~mm}$ away from the specimen-crucible surface; (2) in the specimen, $4 \mathrm{~mm}$ away from the specimen-crucible surface; and (3) in the specimen's center. The measured cooling rates attained were: $R_{800-\text { liq }}=0.587(\mathrm{~K} / \mathrm{s}), R_{\text {liq-sol }}=0.103(\mathrm{~K} / \mathrm{s})$, and $R_{\text {sol- } 470}=0.265(\mathrm{~K} / \mathrm{s})$ for AlCu4Si6 without stirring and for stirring $R_{800-l i q}=0.617(\mathrm{~K} / \mathrm{s}), \mathrm{R}_{\mathrm{liq}-\mathrm{sol}}=0.108(\mathrm{~K} / \mathrm{s})$, and $R_{\text {sol-470 }}=0.281(\mathrm{~K} / \mathrm{s})$. The temperature gradient between a location $4 \mathrm{~mm}$ away from the specimen's surface and the specimen center was: without stirring $\mathrm{G}_{800-\mathrm{liq}}=0.196(\mathrm{~K} / \mathrm{mm})$ and $\mathrm{G}_{\mathrm{liq}-470}=0.132(\mathrm{~K} / \mathrm{mm})$ and with flow $\mathrm{G}_{800-\mathrm{liq}}=0.206(\mathrm{~K} / \mathrm{mm})$ and $\mathrm{G}_{\mathrm{liq}-470}=0.141$ $(\mathrm{K} / \mathrm{mm})$. These measurements together with measurement of solidification time (Table 1) showed that heating and cooling of the crucible and specimen provided continuous simultaneous solidification and slow cooling within the entire specimen by using a low cooling 
rate and low temperature gradient, leading to the formation of equiaxed dendrites in the absence of RMF stirring.

Table 1. Microstructure parameters measured on investigated micrographs of AlCu alloys.

\begin{tabular}{|c|c|c|c|c|c|c|c|c|c|}
\hline \multirow{3}{*}{$\begin{array}{l}\text { Aluminium } \\
\text { Alloys }\end{array}$} & \multirow{3}{*}{$\begin{array}{c}\text { RMF } \\
\text { [mT] } \\
\text { \{Solid. } \\
\text { Time [s]\} }\end{array}$} & \multicolumn{8}{|c|}{ Microstructure Parameters } \\
\hline & & \multicolumn{2}{|c|}{ Dendrites } & \multicolumn{2}{|c|}{ Fe-Phases $\left(\beta-\mathrm{Al}_{5} \mathrm{FeSi}\right)$} & \multicolumn{2}{|c|}{ Mn-Phases } & \multirow{2}{*}{$\begin{array}{c}\begin{array}{c}\text { AlSi } \\
\text { Eutectics }\end{array} \\
\lambda_{\text {Eut }}[\mu \mathrm{m}]\end{array}$} & \multirow{2}{*}{$\begin{array}{c}\mathrm{Al}_{2} \mathrm{Cu} \\
\lambda_{\mathrm{Al} 2 \mathrm{Si}}[\mu \mathrm{m}]\end{array}$} \\
\hline & & $\begin{array}{c}\lambda_{\text {SDAS }} \\
{[\mu \mathrm{m}]}\end{array}$ & $\mathrm{Sv}\left[\mu \mathrm{m}^{-1}\right]$ & $\mathrm{L}_{\beta}[\mu \mathrm{m}]$ & $\mathrm{n}_{\beta}\left[\mathrm{mm}^{-2}\right]$ & $\mathrm{L}_{\mathrm{Mn}}[\mu \mathrm{m}]$ & $\begin{array}{c}\mathrm{n}_{\mathrm{Mn}} \\
{\left[\mathrm{mm}^{-2}\right]}\end{array}$ & & \\
\hline \multirow[b]{2}{*}{$\mathrm{AlCu} 4$} & $0\{552\}$ & $\begin{array}{l}232[16.4] \\
(34 / 660)\end{array}$ & $\begin{array}{c}0.027 \\
{[0.002]}\end{array}$ & - & - & - & - & - & $\begin{array}{l}2.53[0.2] \\
(2.0-2.8)\end{array}$ \\
\hline & $11\{471\}$ & $\begin{array}{c}145[4.4] \\
(26 / 242) \\
(-37 \%)\end{array}$ & $\begin{array}{c}0.016 \\
{[0.002]} \\
(-41 \%)\end{array}$ & - & - & - & - & - & $\begin{array}{c}2.27[0.2] \\
(1.7-2.7) \\
(-10.3 \%)\end{array}$ \\
\hline \multirow[b]{2}{*}{ AlCu4Si6 } & $0\{547\}$ & $\begin{array}{c}99[5.0] \\
(20 / 292)\end{array}$ & $\begin{array}{c}0.044 \\
{[0.002]}\end{array}$ & - & - & - & - & $39[4.7]$ & $\begin{array}{l}5.72[0.5] \\
(4.8-7.3)\end{array}$ \\
\hline & $11\{463\}$ & $\begin{array}{c}88[6.5] \\
(21 / 235) \\
(-11 \%)\end{array}$ & $\begin{array}{c}0.027 \\
{[0.001]} \\
(-38 \%)\end{array}$ & - & - & - & - & $\begin{array}{l}38[3.9] \\
(-2.5 \%)\end{array}$ & $\begin{array}{c}8.05[1.5] \\
(5.4-11.8) \\
(52.7 \%)\end{array}$ \\
\hline \multirow[b]{2}{*}{$\mathrm{AlCu} 4 \mathrm{Si} 6 \mathrm{Fe} 1$} & $0\{627\}$ & $\begin{array}{l}79[10.3] \\
(20 / 238)\end{array}$ & $\begin{array}{c}0.050 \\
{[0.003]}\end{array}$ & $\begin{array}{c}115[7.1] \\
(936)\end{array}$ & 71 & - & - & $12.4[2.0]$ & $\begin{array}{l}9.07[0.6] \\
(8.1-11.3)\end{array}$ \\
\hline & $11\{548\}$ & $\begin{array}{c}80 \text { [7.1] } \\
(22 / 201) \\
(1 \%)\end{array}$ & $\begin{array}{c}0.032 \\
{[0.001]} \\
(-36 \%)\end{array}$ & $\begin{array}{c}77[5.9] \\
(1484) \\
(-33 \%)\end{array}$ & $113(59 \%)$ & - & - & $\begin{array}{c}14.3[1.9] \\
(15.3 \%)\end{array}$ & $\begin{array}{l}7.45[1.0] \\
(5.1-10.0) \\
(-17.9 \%)\end{array}$ \\
\hline \multirow[b]{2}{*}{$\begin{array}{c}\mathrm{AlCu} 4 \mathrm{Si} 6 \mathrm{Mn} \\
0.65\end{array}$} & $0\{689\}$ & $\begin{array}{l}100[6.7] \\
(30 / 294)\end{array}$ & $\begin{array}{c}0.043 \\
{[0.001]}\end{array}$ & - & - & $\begin{array}{c}189 \text { [8.7] } \\
(122)\end{array}$ & 0.17 & $32.7[4.3]$ & $\begin{array}{l}5.87[0.3] \\
(5.2-6.3)\end{array}$ \\
\hline & $11\{612\}$ & $\begin{array}{c}80[5.8] \\
(28 / 250) \\
(-20 \%)\end{array}$ & $\begin{array}{c}0.032 \\
{[0.002]} \\
(-26 \%)\end{array}$ & - & - & $\begin{array}{c}109[6.5] \\
(188) \\
(-42 \%)\end{array}$ & $\begin{array}{c}0.26 \\
(53 \%)\end{array}$ & $\begin{array}{c}30.5[2.9] \\
(-6.7 \%)\end{array}$ & $\begin{array}{c}6.62[0.7] \\
(5.6-8.8) \\
(12.8 \%)\end{array}$ \\
\hline \multirow[b]{2}{*}{$\begin{array}{l}\mathrm{AlCu} 4 \mathrm{Si} F \mathrm{Fe} 1 \\
\mathrm{Mn} 0.65\end{array}$} & $0\{671\}$ & $\begin{array}{c}85 \text { [8.7] } \\
(27 / 293)\end{array}$ & $\begin{array}{c}0.047 \\
{[0.001]}\end{array}$ & $\begin{array}{c}80[5.5] \\
(276)\end{array}$ & 21 & $\begin{array}{c}315 \text { [17.3] } \\
(129)\end{array}$ & 0.18 & $14.3[2.0]$ & $\begin{array}{l}8.41[1.3] \\
(7.2-13.7)\end{array}$ \\
\hline & $11\{608\}$ & $\begin{array}{c}79[6.0] \\
(36 / 295) \\
(-7 \%)\end{array}$ & $\begin{array}{c}0.036 \\
{[0.002]} \\
(-23 \%)\end{array}$ & $\begin{array}{c}75[5.6] \\
(912) \\
(-6 \%)\end{array}$ & $69(229 \%)$ & $\begin{array}{l}323[20.3] \\
(53)(3 \%)\end{array}$ & $\begin{array}{c}0.08 \\
(-56 \%)\end{array}$ & $\begin{array}{l}13.2[2.1] \\
(-7.7 \%)\end{array}$ & $\begin{array}{c}8.59[0.7] \\
(6.7-10.0) \\
(2.1 \%)\end{array}$ \\
\hline \multirow[b]{2}{*}{ AlCu10Si10 } & $0\{724\}$ & $\begin{array}{c}56 \text { [7.5] } \\
(33 / 306)\end{array}$ & $\begin{array}{c}0.066 \\
{[0.002]}\end{array}$ & - & - & - & - & $24.1[3.2]$ & $\begin{array}{c}13.70[1.2] \\
(10.9-17.3)\end{array}$ \\
\hline & $11\{637\}$ & $\begin{array}{c}53[4.8] \\
(25 / 171) \\
(-5 \%)\end{array}$ & $\begin{array}{c}0.043 \\
{[0.003]} \\
(-35 \%)\end{array}$ & - & - & - & - & $\begin{array}{c}29.7[4.7] \\
(23.2 \%)\end{array}$ & $\begin{array}{c}12.38[1.6] \\
(8.5-13.8) \\
(-9.6 \%)\end{array}$ \\
\hline \multirow[b]{2}{*}{ AlCu10Si10Fe1 } & $0\{709\}$ & $\begin{array}{c}66 \text { [7.2] } \\
(31 / 239)\end{array}$ & $\begin{array}{c}0.047 \\
{[0.005]}\end{array}$ & $\begin{array}{l}524 \text { [46.3] } \\
\quad(231)\end{array}$ & 4.2 & - & - & $17.5[3.0]$ & $\begin{array}{c}13.08[1.6] \\
(10.1-17.6)\end{array}$ \\
\hline & $11\{607\}$ & $\begin{array}{c}57[4.2] \\
(28 / 220) \\
(-13 \%)\end{array}$ & $\begin{array}{c}0.071 \\
{[0.008]} \\
(51 \%)\end{array}$ & $\begin{array}{c}642[43.4] \\
(208)(23 \%)\end{array}$ & $3.7(-12 \%)$ & - & - & $\begin{array}{c}18.9[2.6] \\
(8.0 \%)\end{array}$ & $\begin{array}{c}15.38[1.4] \\
(13-21.3) \\
(17.6 \%)\end{array}$ \\
\hline \multirow[b]{2}{*}{ AlCu4Si6Fe2 } & $0\{673\}$ & $\begin{array}{c}\text { No } \\
\text { dendrites }\end{array}$ & $\begin{array}{c}0.056 \\
{[0.004]}\end{array}$ & $\begin{array}{c}66[7.2] \\
(3990)\end{array}$ & 303 & - & - & $14.6[1.8]$ & $\begin{array}{l}6.04[0.9] \\
(4.4-9.0)\end{array}$ \\
\hline & $11\{597\}$ & $\begin{array}{c}\text { No } \\
\text { dendrites }\end{array}$ & $\begin{array}{c}0.041 \\
{[0.004]} \\
(-27 \%)\end{array}$ & $\begin{array}{c}116 \text { [15.6] } \\
(1146) \\
(76 \%)\end{array}$ & $87(-71 \%)$ & - & - & $\begin{array}{c}19.3[2.3] \\
(32.2 \%)\end{array}$ & $\begin{array}{c}7.92[1.3] \\
(3.6-11.0) \\
(31.1 \%)\end{array}$ \\
\hline \multirow[b]{2}{*}{ AlCu4Si6Mn2 } & $0\{705\}$ & $\begin{array}{c}94 \text { [4.7] } \\
(27 / 223)\end{array}$ & $\begin{array}{c}0.036 \\
{[0.004]}\end{array}$ & - & - & $\begin{array}{c}268 \text { [15.2] } \\
\quad(205)\end{array}$ & 0.27 & $29.5[3.6]$ & $\begin{array}{l}7.90[0.6] \\
(6.4-9.0)\end{array}$ \\
\hline & $11\{611\}$ & $\begin{array}{c}85[4.8] \\
(32 / 285) \\
(-9 \%)\end{array}$ & $\begin{array}{c}0.026 \\
{[0.003]} \\
(-28 \%)\end{array}$ & - & - & $\begin{array}{c}216 \\
{[14.2](-19 \%)}\end{array}$ & $0.16(-41 \%)$ & $\begin{array}{l}26.3[2.5] \\
(-10.8 \%)\end{array}$ & $\begin{array}{c}9.55[1.0] \\
(6.5-12.4) \\
(20.9 \%)\end{array}$ \\
\hline
\end{tabular}

(1) Curly brackets $\{$. . . \} present the solidification time (s); (2) Brackets [ . . ] present the standard deviation, (3) Parentheses ( ... / ... ) present numbers of grains inspected and dendrite arms counted; (4) Parentheses ( . . \% ) present the variation of the parameters in percent under electromagnetic stirring; (5) Parentheses ( . . _ . . ) present the range of measured eutectic spacings; (6) Parentheses ( ... ) present the numbers of intermetallic phases counted. 
A rotating magnetic field RMF was generated by electromagnetic coils powered from an autotransformer with $10 \mathrm{~A}$ and $45 \mathrm{~V}$ at a frequency of $50 \mathrm{~Hz}$, and achieved a magnetic flux density of $11 \mathrm{mT}$ (Magnetic Field Meter AC/DC, MF100, Extech Instruments, Nashua, New Hampshire, NH, US). The rotational speed was estimated (by camera recording of the rotating sample cylinder) to be $2.1 \mathrm{~s}^{-1}$.

The samples produced (Figure 1), were cut at a height of $10 \mathrm{~mm}$ from the bottom for the transverse cross-section (Figure 1) and $20 \mathrm{~mm}$ from the bottom for the longitudinal section (Figure 1). The microsections were prepared using a standard metallographic procedure and observed with a light optical microscope LOM (Nikon Eclipse MA200, Tokyo, Japan) and imaging software (NIS Elements 5.21.03, Japan). In total, 36 sections from 18 experiments were analyzed ( 9 alloys, each without and with forced flow). Analysis was performed using the ImageJ 1.51a software (Fiji, National Institutes of Health, Bethesda, Maryland, MD, USA) on the cross- and long-sections in nine specified areas (white filled rectangles in Figure 1) and in six larger areas (dashed line rectangles) using magnifications of $50 \times, 100 \times, 200 \times$ and $500 \times$ and the image stitching technique.

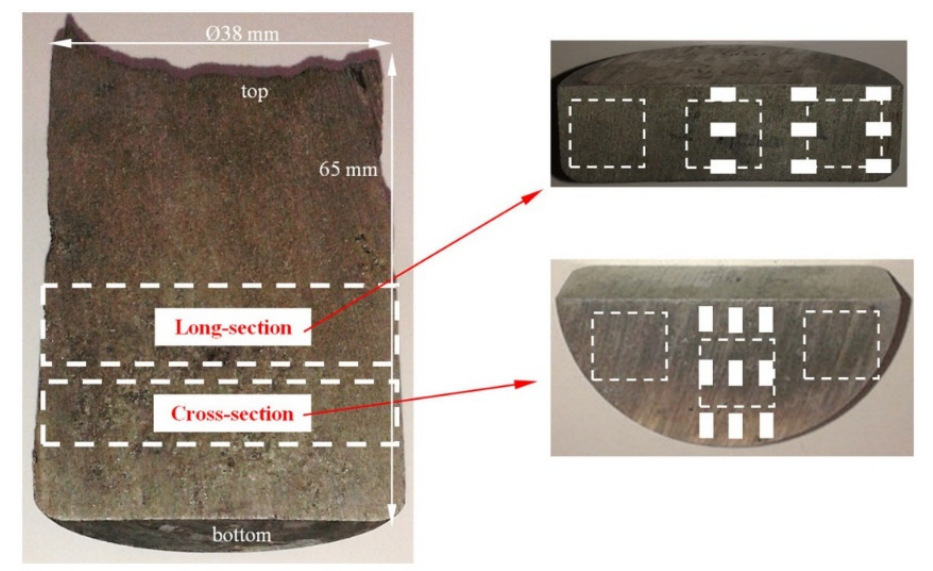

Figure 1. Scheme of cutting the long- and cross-section in the ingot specimen. The placement of the microstructure parameter (Table 1) measurement on the long- and cross-section. The white fulfilled rectangles show 18 ( 9 on cross- and 9 on long-section) areas for the parameter measurement (magnification $50 \times$ and $200 \times$ ). The dashed line rectangles show 6 measurement regions magnified by $50 \times$.

For each region on the transverse and longitudinal section, the following parameters were determined: specific surface of dendrites $S_{\mathrm{v}}$, secondary dendrite arm spacing $\lambda_{2}$, number density $n_{\beta}$ and average length $L_{\beta}$ of $\beta-\mathrm{Al}_{5}$ FeSi platelets, number density $n_{M n}$ and average overall dimensions $\mathrm{L}_{\mathrm{Mn}}$ of the $\alpha-\mathrm{Al}_{15} \mathrm{Si}_{2} \mathrm{Mn}_{4}$ phases. In addition to this, the spacing $\lambda_{\mathrm{Al} 2 \mathrm{Cu}}$ for the $\mathrm{Al}_{2} \mathrm{Cu}$ eutectic phase and the eutectic spacing $\lambda_{\mathrm{E}}$ for $\mathrm{Al}-\mathrm{Si}$ eutectics were measured. The secondary dendrite arm spacing $\lambda_{2}$ was measured along the primary dendrite stem by averaging the distance between 10 and 50 adjacent side branches. The specific surface of the dendrites $S_{\mathrm{v}}$ was estimated from the measured enclosed area and the perimeter of the $\alpha$-Al dendrites. In the measurement of about $9000 \mathrm{Fe}-$ rich intermetallics, only needles with a length/thickness ratio $>5$ and thickness $>3 \mu \mathrm{m}$ were considered and average length was calculated. In the measurement of 650 complex-shaped Mn-rich intermetallics, the author considered the overall dimensions of each precipitate and calculated the average overall dimension. The spacing $\lambda_{\mathrm{Al} 2 \mathrm{Cu}}$ was measured by averaging the distance $\mathrm{L}_{\mathrm{Al} 2 \mathrm{Cu}}$ between adjacent plates; the same was measured for AlSi eutectic phases.

In this paper, the author studied precipitations, such as dendritic $\alpha$-Al, AlSieutectic, $\mathrm{Al}_{2} \mathrm{Cu}$, needle or platelet shaped $\beta-\mathrm{Al}_{9} \mathrm{Fe}_{2} \mathrm{Si}_{2}$ and $\beta-\mathrm{Al}_{8} \mathrm{Fe}_{2} \mathrm{Si}$, and complex manganese $\mathrm{Al}_{15} \mathrm{Si}_{2} \mathrm{Mn}_{4}$ phases; these are all well known from many investigations (e.g., in [1-6,24,25,57-63]) concerning aluminum alloy phases. In order to determine 
the sequence of precipitation of phases, property diagrams, Scheil solidification, and the ternary phase diagram were calculated for selected and examined alloys using the Thermo-Calc Software [26], which is widely used by materials scientists and engineers to generate material property data and gain insight into materials.

\section{Results}

The microstructure on the cross- and long-sections of specimens was investigated on micrographs using a light optical microscope (LOM), and all assumed, measured and calculated parameters were collected in a table. The property diagrams, Scheil solidification and the ternary phase diagram for the investigated alloys were calculated in the ThermoCalc [26].

\subsection{Microstructure}

Figure 2 shows, for the AlCu4 alloy, micrographs of typical structure obtained in experiments for solidification without and with forced convection, where for solidification without electromagnetic stirring clearly formed $\alpha$-Al dendrites characteristic are, whilst for melt flow, $\alpha$-Al formed as rosettes and rarely as spheroids (globular forms) or as not fully formed dendrites. Figure 3 shows, for the AlCu4Si alloy, $\alpha$-Al dendrites (white), $(\alpha-\mathrm{Al})$-Si eutectic (very dark grey) and $\mathrm{Al}_{2} \mathrm{Cu}$ phase (bright grey) for solidification without (formed dendrites) and with stirring (globular forms). The flow effect is also clearly visible for other alloys, e.g., AlCu4Si6Fe1 (Figure 4) and AlCu4Si6mn0.65 (Figure 5) alloys. Figure 6 presents, for the AlCu4Si6Fe1 alloy, micrographs of specimens solidified with stirring, with very visible dendrites changed into rosettes, minor dendrites and occasionally spheroids (white), $\beta-\mathrm{Al}_{5} \mathrm{FeSi}$ phases (dark grey) in the form of needles spread over the entire sample, and only slightly visible, very small $\beta$ needles. Figure $6 \mathrm{~b}$ also shows $\mathrm{Al}_{2} \mathrm{Cu}$ (bright grey) phases arranged between $\beta$ platelets and white $\alpha$-Al rosettes, and also ( $\alpha$-Al)-Si eutectic (very dark grey). For the AlCu4Si6Mn0.65 alloy, $\beta$ needles were replaced by Mn-rich phases with complex shapes (Figure 7). The micrographs for the AlCu10Si10Fe1 alloy show very large $\beta-\mathrm{Al}_{5} \mathrm{FeSi}$ phases with a length reaching more than $1000 \mu \mathrm{m}$ (Figure 8a) and also small $\beta$ platelets (Figure 8b). Figure 9a presents unusual non-dendritic microstructures formed in the $\mathrm{AlCu} 4 \mathrm{Si} 6 \mathrm{Fe} 2$ alloy for solidification without stirring, on which, beside pronounced $\beta$, very short and thin $\beta-\mathrm{Al}_{5} \mathrm{FeSi}$ (Figure $9 \mathrm{~b}$ ) are also visible. Figure 10a shows an untypical structure in the AlCu4Si6Fe2 alloy for solidification with stirring, where $\alpha-\mathrm{Al}$ phase seems to surround iron-rich phases. A similar effect is shown Figures 10b and 11a,b, where Mn-rich phases with complex shapes are enclosed by $\alpha$-Al. For almost all alloys solidified with forced flow, dendrites changed into rosettes, minor dendrites and occasionally into spheroids.

\subsection{Parameters Characterising the Microstructure}

The microstructure evolution caused by the forced flow is characterized by parameters counted and measured in specific areas (Figure 1), three or nine (small white rectangles) areas on the long section and, three or nine on the cross-section. The results are almost equal in all small 18 figures and no tendency was found across the specimens. Such methodology provided reliable results presented in Table 1 along with a proper overview of all the specimens. For AlCu4, the induced fluid flow caused an approximately $37 \%$ decrease in secondary dendrite arm spacing $\lambda_{2}$, from 232 to $145 \mu \mathrm{m}$, for the other alloys the decrease was about $5-20 \%$, and for $\mathrm{AlCu} 4 \mathrm{Si6Fe}$ it seems unchanged and reaches 79 and $80 \mu \mathrm{m}$. The evolution from a dendritic to a rosette shape, well visible in Figures 2-6, results in a decrease in the specific surface $S_{\mathrm{v}}$ of the $\alpha$-Al primary phase for almost all alloys. For the AlCu4 alloy, $\mathrm{S}_{\mathrm{v}}$ is $0.027 \mu \mathrm{m}^{-1}$ for solidification without stirring, and $0.016 \mu \mathrm{m}^{-1}$ with flow, whilst, for the other alloys, stirring caused a decrease of about $23-38 \%$. Only for one AlCu10Si10Fe1 alloy, the specific surface increased from 0.047 to $0.071 \mu \mathrm{m}^{-1}$. The solidification time decreased under melt flow for all the studied alloys. 


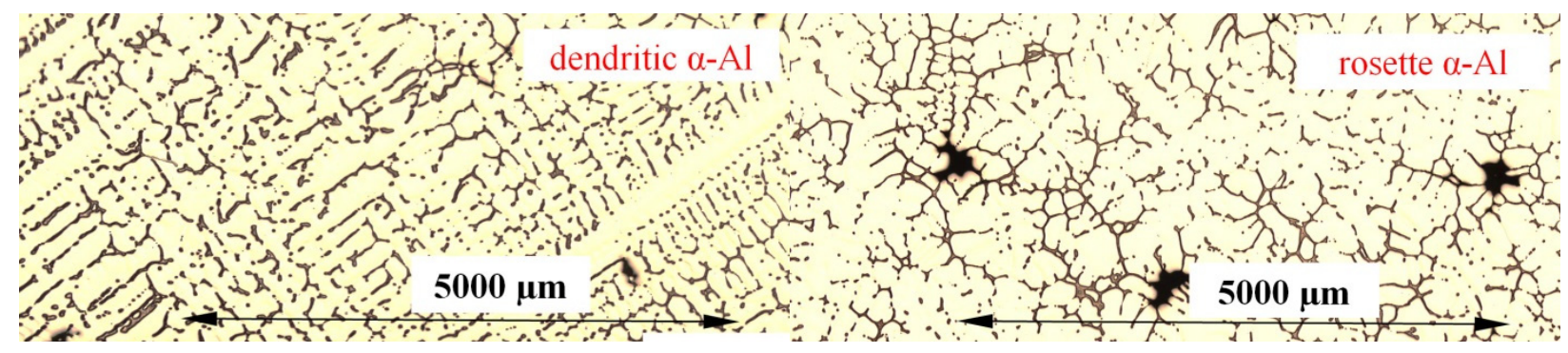

(a)

(b)

Figure 2. Microstructures of the AlCu4 specimen solidified: (a) without and (b) with electromagnetic stirring. LOM, magnification $50 \times$.

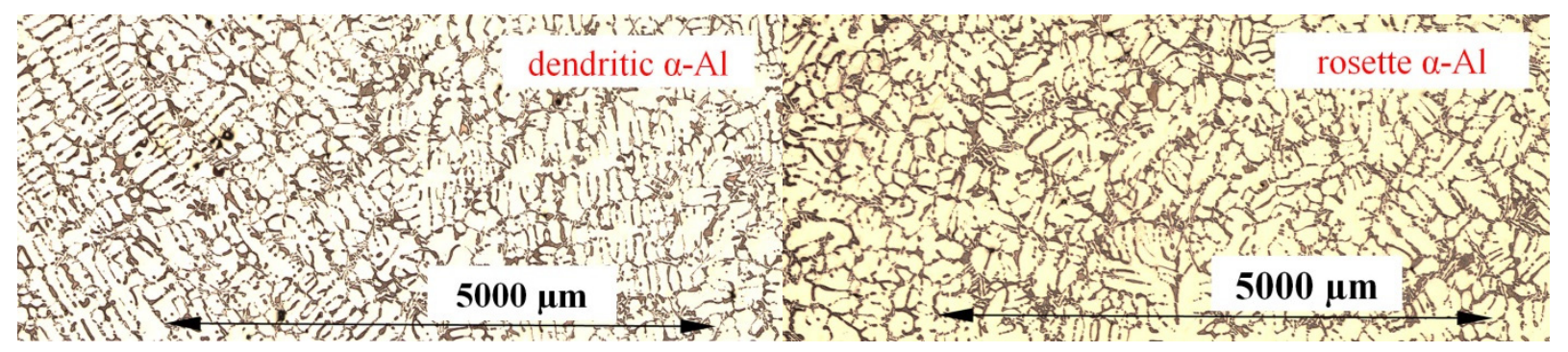

(a)

(b)

Figure 3. Microstructures of the AlCu4Si6 specimen solidified: (a) without and (b) with electromagnetic stirring. LOM, magnification $50 \times$.

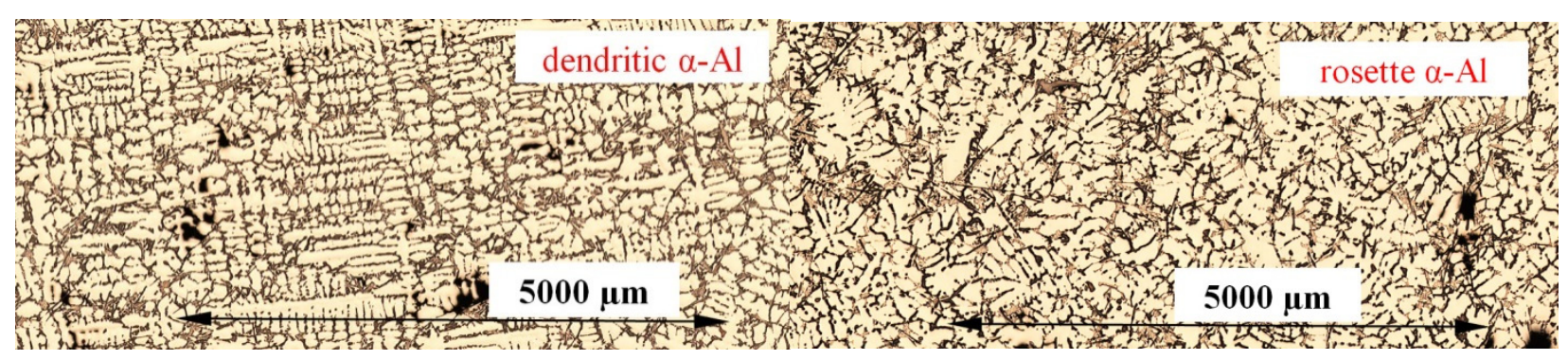

(a)

(b)

Figure 4. Microstructures of the AlCu4Si6Fe1 specimen solidified: (a) without and (b) with electromagnetic stirring. LOM, magnification $50 \times$.

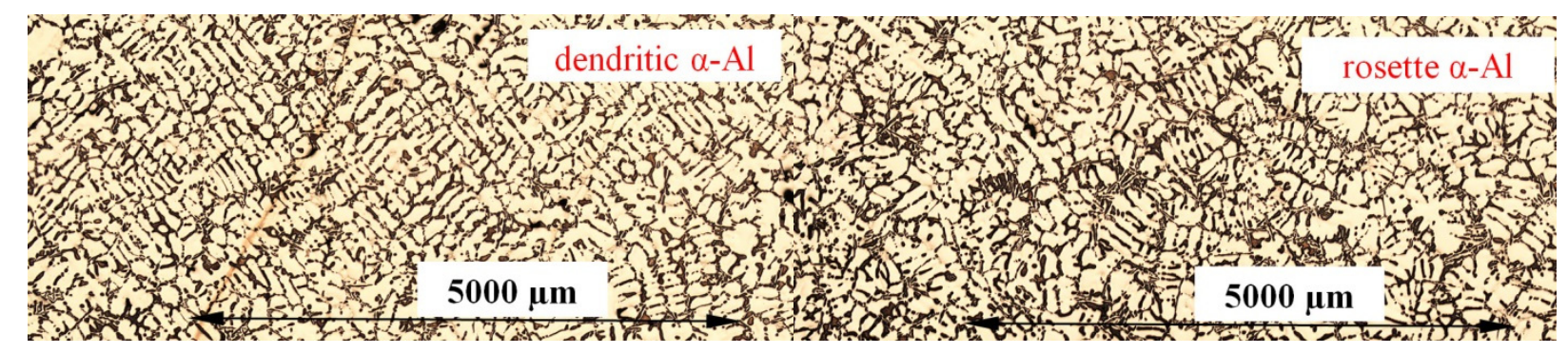

(a)

(b)

Figure 5. Microstructures of the AlCu4Si6Mn0.65 specimen solidified: (a) without and (b) with electromagnetic stirring. LOM, magnification $50 \times$. 


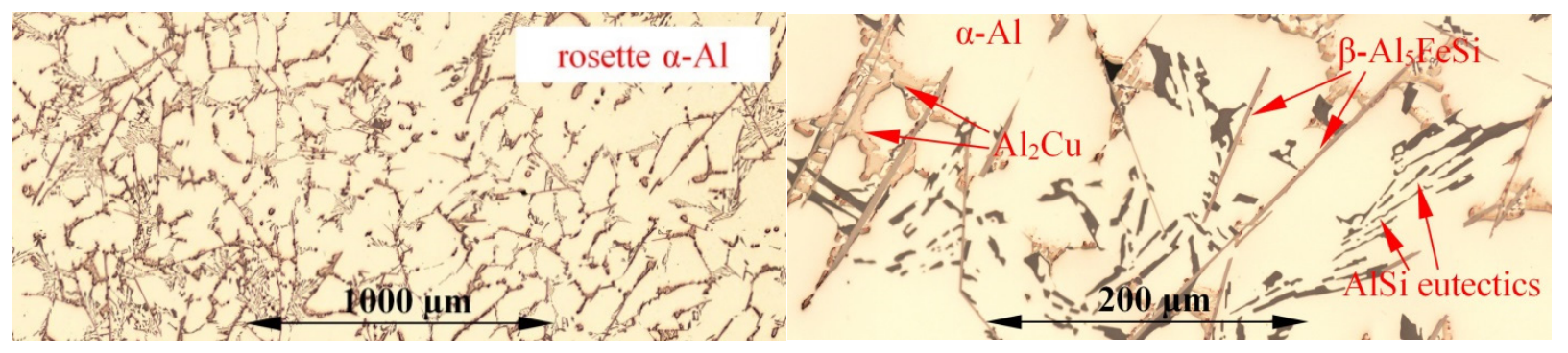

(a)

(b)

Figure 6. Microstructures of the AlCu4Si6Fe1.0 specimen solidified with electromagnetic stirring. LOM: (a) magnification 100 and (b) magnification $500 \times$.

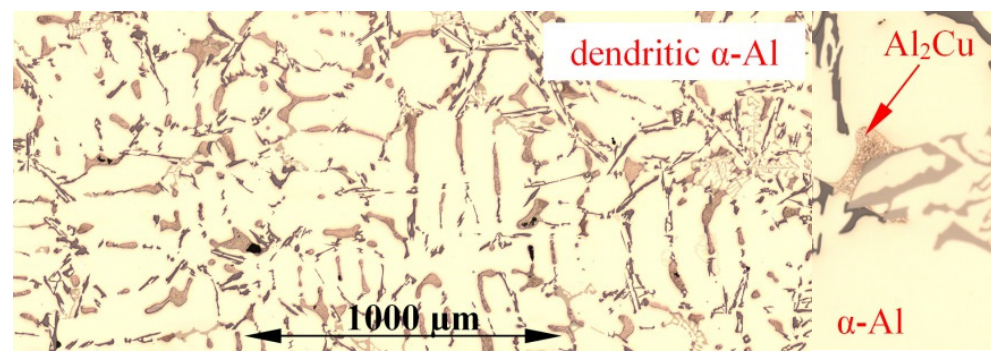

(a)

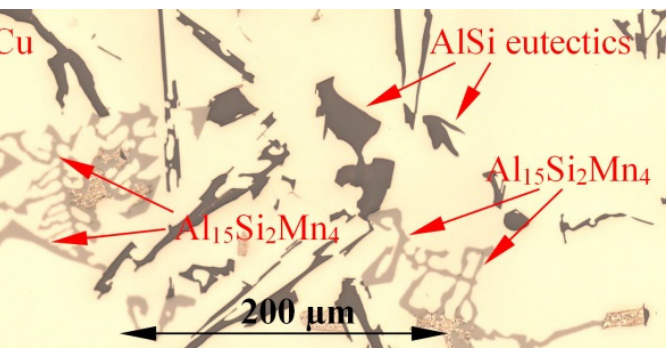

(b)

Figure 7. The microstructures of the AlCu4Si6Mn0.65 specimen solidified without electromagnetic stirring. LOM: (a) magnification 100 and (b) magnification $500 \times$.

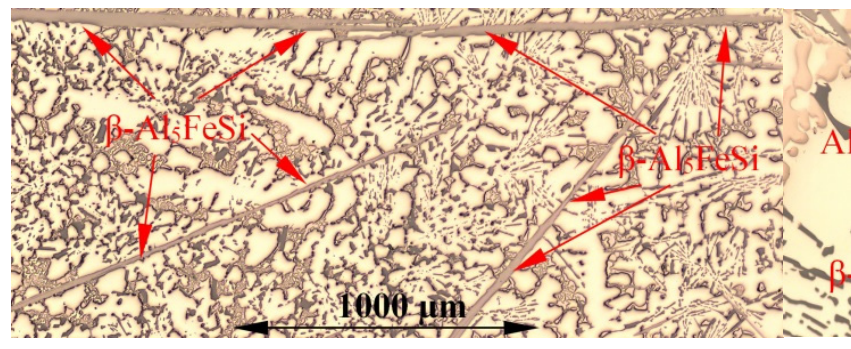

(a)

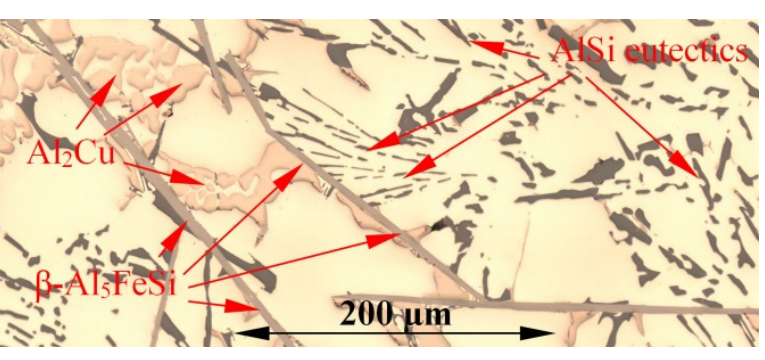

(b)

Figure 8. Mmicrostructures of the AlCu10Si10Fe1.0 specimen solidified with electromagnetic stirring. LOM: (a) magnification 100 and (b) magnification $500 \times$.

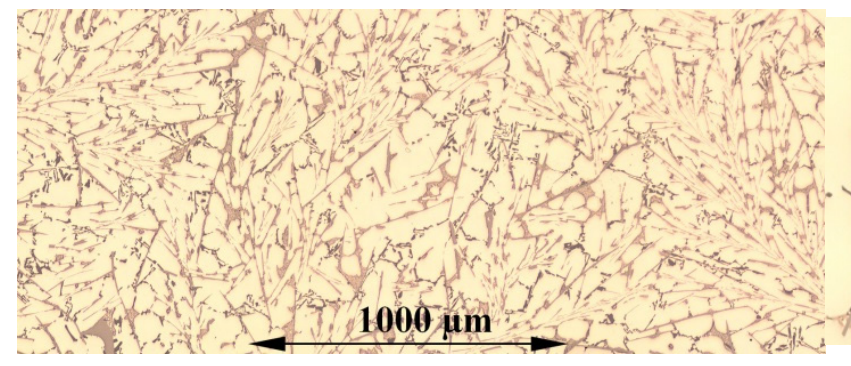

(a)

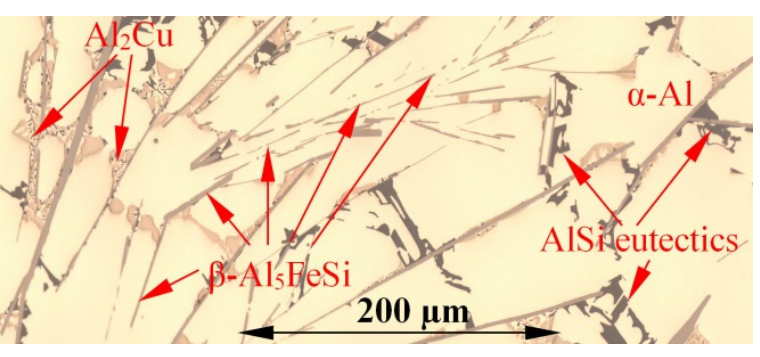

(b)

Figure 9. Microstructures of the AlCu4Si6Fe2.0 specimen solidified without electromagnetic stirring. LOM: (a) magnification 100 and (b) magnification $500 \times$. 


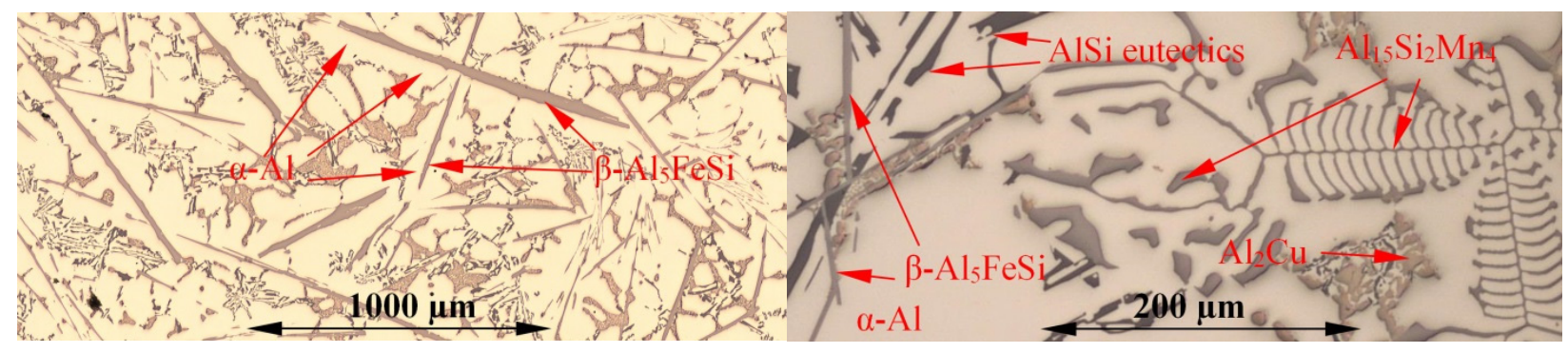

(a)

(b)

Figure 10. Microstructures of: (a) the AlCu4Si6Fe2.0 specimen solidified with electromagnetic stirring, LOM magnification $100 \times$ and $(\mathbf{b})$ the AlCu4Si6Fe1.0Mn0.65 specimen solidified without electromagnetic stirring, LOM magnification $500 \times$.

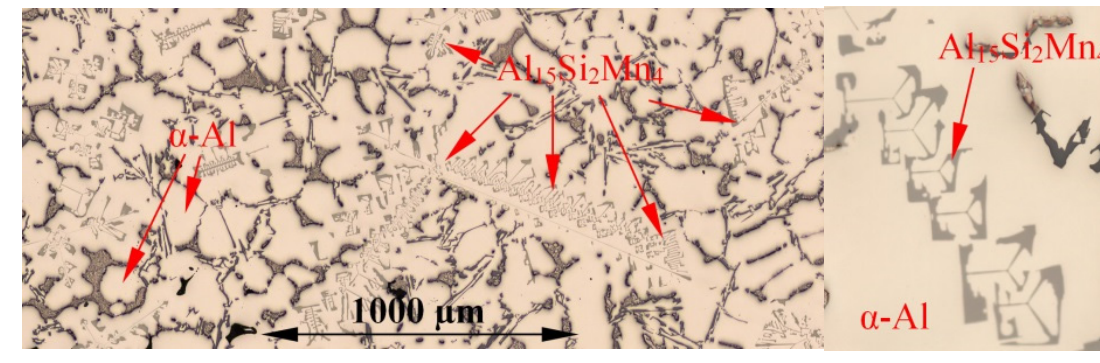

(a)

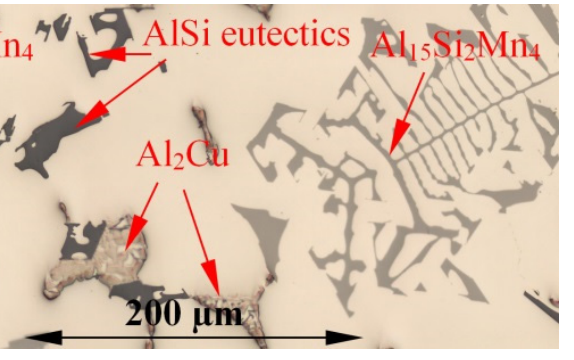

(b)

Figure 11. Microstructures of the AlCu4Si6Mn2.0 specimen solidified without electromagnetic stirring. LOM: (a) magnification $100 \times$ and (b) magnification $500 \times$.

Fe-rich intermetallics were characterized by number density $\mathrm{n}_{\beta}$ and by average length $L_{\beta}$. It is clear (Table 1 ) that stirring caused the shortening of $\beta$ phases for the AlCu4Si6Fe1 alloy, where average length $\mathrm{L}_{\beta}$ decreased by $33 \%$-from 115 to $77 \mu \mathrm{m}$, while for $\mathrm{AlCu} 10 \mathrm{Si} 10 \mathrm{Fe} 1$ and $\mathrm{AlCu} 4 \mathrm{Si} 6 \mathrm{Fe} 1$ it increased by $23 \%$ and $76 \%$, respectively. The number density $n_{\beta}$ acted the other way round, for the AlCu4Si6Fe1 alloy it increased by $59 \%$-from $71 \mathrm{~mm}^{-2}$ to $113 \mathrm{~mm}^{-2}$, while for AlCu10Si10Fe1 and AlCu4Si6Fe1 it decreased by $12 \%$ and $71 \%$, respectively.

Mn-rich precipitates were characterized by the measurement of the number density $\mathrm{n}_{\mathrm{Mn}}$ and the average overall dimension $\mathrm{L}_{\mathrm{Mn}}$ of the mostly complex shape phases. Stirring decreased the average overall $\mathrm{L}_{\mathrm{Mn}}$ dimension by about $42 \%$-from 189 to $109 \mu \mathrm{m}$ and increased the number density from 0.17 to $0.26 \mathrm{~mm}^{-2}$ for the AlCu4Si6Mn0.65 alloy. For the AlCu4Si6Fe1Mn0.65 alloy, the average overall $\mathrm{L}_{\mathrm{Mn}}$ dimension remained almost unchanged, by 315 and $323 \mu \mathrm{m}$, while the number density decreased from 0.18 to $0.08 \mathrm{~mm}^{-2}$.

The effect of forced flow on ( $\alpha-\mathrm{Al})$-Si eutectic is unclear; there is no direct modification in the eutectic spacing $\lambda_{E}$, both increases and decreases were observed for individual alloys. For the AlCu4Si6Fe1 alloy, the eutectic spacing $\lambda_{\mathrm{E}}$ increased by $15.3 \%$ from 12.4 to $14.3 \mu \mathrm{m}$, with the standard deviation values of 2.0 and $1.9 \mu \mathrm{m}$. For the binary eutectic $\left(\alpha-\mathrm{Al}+\mathrm{Al}_{2} \mathrm{Cu}\right)$ denoted as $\mathrm{Al}_{2} \mathrm{Cu}$, we measured the spacing, while for the ternary eutectic $\left(\alpha-\mathrm{Al}+\mathrm{Al}_{2} \mathrm{Cu}+\beta\right.$ $\mathrm{Si}$ ) we abandoned the phase measurement, because the available thermodynamic model [26] did not show the phase clearly enough and the supporting information on the sequence, amount and characteristic temperatures during solidification was unclear. The effect of melt flow on $\mathrm{Al}_{2} \mathrm{Cu}$ is unclear, and both decreases and increases in the $\lambda_{\mathrm{Al} 2 \mathrm{Cu}}$ spacing were observed. For the AlCu $4 S i 6$ alloy, the $\lambda_{\mathrm{Al} 2 \mathrm{Cu}}$ spacing increased by $52.7 \%$-from 5.72 to $8.05 \mu \mathrm{m}$ - with the standard deviation values of 0.5 and $1.5 \mu \mathrm{m}$.

The measurement carried out on large number of intermetallics and grains allowed the results to be of good quality. The square brackets (Table 1) present the standard deviation, while the parentheses show the numbers of inspected grains and dendrite arms, e.g., for AlCu4Si6Fe1Mn0.65 solidified with forced convection, 36 grains, 295 dendrite arms and 912 $\beta-\mathrm{Al}_{5} \mathrm{FeSi}$ intermetallic phases were measured, whereby the standard deviation for the average 
length $L_{\beta}=75 \mu \mathrm{m}$ was $5.6 \mu \mathrm{m}$. Stirring resulted in the $-7 \%$ variation in $\lambda_{2}$, from 85 to $79 \mu \mathrm{m}$ (standard deviation was 8.7 and $6.0 \mu \mathrm{m}$ ) and a reduction in solidification time from 671 to $608 \mathrm{~s}$.

\subsection{Precipitation Sequence}

The sequence of precipitation of the phases present for all the studied alloys was based on thermodynamic calculations performed in the Thermo-Calc [26] software, presented in Table 2 and in Figures 12-14, and for the selected alloys described in detail below.

Table 2. Precipitation sequence in studied AlCu alloys.

\begin{tabular}{|c|c|c|c|c|c|c|c|c|c|}
\hline \multirow[b]{2}{*}{ Alloy } & \multirow[b]{2}{*}{ Reaction } & \multirow{2}{*}{$\begin{array}{l}\text { Temperature } \\
\text { Range of } \\
\text { Reaction }\end{array}$} & \multicolumn{7}{|c|}{ Mass Fraction of Solid Phases [\%] (the Rest Is Liquid Alloy) at the Temperature [ $\left.{ }^{\circ} \mathrm{C}\right]$} \\
\hline & & & Temperature & $\alpha-\mathrm{Al}$ & $\begin{array}{c}\beta- \\
\mathrm{Al}_{9} \mathrm{Fe}_{2} \mathrm{Si}_{2}\end{array}$ & $\begin{array}{c}\beta- \\
\mathrm{Al}_{8} \mathrm{Fe}_{2} \mathrm{Si}\end{array}$ & $\mathrm{Al}_{15} \mathrm{Si}_{2} \mathrm{Mn}_{4}$ & Eut Si & $\mathrm{Al}_{2} \mathrm{Cu}$ \\
\hline \multirow{2}{*}{$\mathrm{AlCu} 4$} & $\mathrm{~L} \rightarrow \alpha-\mathrm{Al}+\mathrm{L}$ & $649.8-571.6$ & 571.6 & 100 & - & - & - & - & 0.0 \\
\hline & $\alpha-\mathrm{Al} \rightarrow \alpha-\mathrm{Al}+\mathrm{Al}_{2} \mathrm{Cu}$ & $571.6-20.0$ & 20 & 92.60 & - & - & - & - & 7.40 \\
\hline \multirow{3}{*}{$\mathrm{AlCu} 4 \mathrm{Si} 6$} & $\mathrm{~L} \rightarrow \alpha-\mathrm{Al}+\mathrm{L}$ & $611.8-562.9$ & 562.9 & 51.99 & - & - & - & 0.0 & 0.0 \\
\hline & $\mathrm{L} \rightarrow \mathrm{L}+\alpha-\mathrm{Al}+\mathrm{Si}$ & $562.9-526.3$ & 526.3 & 94.98 & - & - & - & 5.02 & 0.0 \\
\hline & $\alpha-\mathrm{Al}+\mathrm{Si} \rightarrow \alpha-\mathrm{Al}+\mathrm{Al}_{2} \mathrm{Cu}+\mathrm{Si}$ & $507.3-20.0$ & 20 & 86,60 & - & - & - & 6.00 & 7.40 \\
\hline \multirow{4}{*}{ AlCu4Si6Fe1 } & $\mathrm{L} \rightarrow \alpha-\mathrm{Al}+\mathrm{L}$ & $608.9-601.1$ & 601.1 & 13.55 & 0.0 & - & - & 0.0 & 0.0 \\
\hline & $\mathrm{L} \rightarrow \alpha-\mathrm{Al}+\beta-\mathrm{Al}_{9} \mathrm{Fe}_{2} \mathrm{Si}_{2}$ & $601.1-560.4$ & 560.4 & 52.9 & 3.05 & - & - & 0.0 & 0.0 \\
\hline & $\mathrm{L} \rightarrow \alpha-\mathrm{Al}+\beta-\mathrm{Al}_{9} \mathrm{Fe}_{2} \mathrm{Si}_{2}+\mathrm{Si}$ & $560.4-525.0$ & 525.0 & 91.75 & 3.71 & - & - & 4.54 & 0.0 \\
\hline & $\alpha-\mathrm{Al}+\beta-\mathrm{Al}_{9} \mathrm{Fe}_{2} \mathrm{Si}_{2}+\mathrm{Si}$ & $525.0-20.0$ & 20 & 83.22 & 3.71 & - & - & 5.67 & 7.40 \\
\hline \multirow{4}{*}{ AlCu4Si6Mn0.65 } & $\mathrm{L} \rightarrow \alpha-\mathrm{Al}+\mathrm{L}$ & $610.9-593.6$ & 593.6 & 26.66 & - & - & 0.0 & 0.0 & 0.0 \\
\hline & $\mathrm{L} \rightarrow \alpha-\mathrm{Al}+\mathrm{Al}_{15} \mathrm{Si}_{2} \mathrm{Mn}_{4}$ & $593.6-561.5$ & 561.5 & 51.91 & - & - & 1.07 & 0.0 & 0.0 \\
\hline & $\mathrm{L} \rightarrow \alpha-\mathrm{Al}+\mathrm{Al}_{15} \mathrm{Si}_{2} \mathrm{Mn}_{4}+\mathrm{Si}$ & $561.5-524.1$ & 524.1 & 93.16 & - & - & 2.01 & 4.83 & 0.0 \\
\hline & $\begin{array}{c}\alpha-\mathrm{Al}+\mathrm{Al}_{15} \mathrm{Si}_{2} \mathrm{Mn}_{4}+\mathrm{Si} \rightarrow \alpha-\mathrm{Al}+ \\
\mathrm{Al}_{2} \mathrm{Cu}+\mathrm{Al}_{15} \mathrm{Si}_{2} \mathrm{Mn}_{4}+\mathrm{Si}\end{array}$ & $509.4-20.0$ & 20 & 84.60 & - & - & 2.17 & 5.83 & 7.40 \\
\hline \multirow{5}{*}{ AlCu4Si6Fe1Mn0.65 } & $\mathrm{L} \rightarrow \mathrm{Al}_{15} \mathrm{Si}_{2} \mathrm{Mn}_{4}+\mathrm{L}$ & $625.1-608.8$ & 608.8 & 0.0 & 0.0 & - & 1.16 & 0.0 & 0.0 \\
\hline & $\mathrm{L} \rightarrow \mathrm{Al}_{15} \mathrm{Si}_{2} \mathrm{Mn}_{4}+\mathrm{L}+\alpha-\mathrm{Al}$ & $608.8-576.3$ & 576.3 & 41.31 & 0.0 & - & 3.81 & 0.0 & 0.0 \\
\hline & $\begin{array}{c}\mathrm{L} \rightarrow \mathrm{Al}_{15} \mathrm{Si}_{2} \mathrm{Mn}_{4}+\mathrm{L}+\alpha-\mathrm{Al}+ \\
\quad \beta-\mathrm{Al}_{9} \mathrm{Fe}_{2} \mathrm{Si}_{2}\end{array}$ & $576.3-559.6$ & 559.6 & 51.94 & 1.25 & - & 3.29 & 0.0 & 0.0 \\
\hline & $\begin{aligned} \mathrm{L} \rightarrow & \mathrm{Al}_{15} \mathrm{Si}_{2} \mathrm{Mn}_{4}+\alpha-\mathrm{Al}+ \\
& \beta-\mathrm{Al}_{9} \mathrm{Fe}_{2} \mathrm{Si}_{2}+\mathrm{Si}\end{aligned}$ & $559.6-523.5$ & 523.5 & 90.00 & 1.65 & - & 3.92 & 4.43 & 0.0 \\
\hline & $\begin{array}{c}\mathrm{Al}_{15} \mathrm{Si}_{2} \mathrm{Mn}_{4}+\alpha-\mathrm{Al}+\beta-\mathrm{Al}_{9} \mathrm{Fe}_{2} \mathrm{Si}_{2} \\
+\mathrm{Si} \rightarrow \mathrm{Al}_{15} \mathrm{Si}_{2} \mathrm{Mn} \mathrm{M}_{4}+\alpha-\mathrm{Al}+ \\
\beta-\mathrm{Al}_{9} \mathrm{Fe}_{2} \mathrm{Si}_{2}+\mathrm{Si}+\mathrm{Al}_{2} \mathrm{Cu}\end{array}$ & $513.1-20$ & 20 & 81.22 & 3.71 & - & 2.17 & 5.50 & 7.40 \\
\hline \multirow{4}{*}{ AlCu10Si10 } & $\mathrm{L} \rightarrow \alpha-\mathrm{Al}+\mathrm{L}$ & $560.7-556.9$ & 556.9 & 3.40 & - & - & - & 0.0 & 0.0 \\
\hline & $\mathrm{L} \rightarrow \mathrm{L}+\alpha-\mathrm{Al}+\mathrm{Si}$ & $556.9-521.6$ & 521.6 & 65.35 & - & - & - & 7.71 & 0.0 \\
\hline & $\mathrm{L} \rightarrow \alpha-\mathrm{Al}+\mathrm{Si}+\mathrm{Al}_{2} \mathrm{Cu}$ & $521.6-521.5$ & 521.5 & 78.97 & - & - & - & 9.18 & 11.85 \\
\hline & $\alpha-\mathrm{Al}+\mathrm{Si}+\mathrm{Al}_{2} \mathrm{Cu}$ & $521.5-20.0$ & 20 & 71.51 & - & - & - & 10.00 & 18.49 \\
\hline \multirow{5}{*}{ AlCu10Si10Fe1 } & $\mathrm{L} \rightarrow \beta-\mathrm{Al}_{9} \mathrm{Fe}_{2} \mathrm{Si}_{2}+\mathrm{L}$ & $610.0-559.6$ & 559.6 & 0.0 & 2.51 & - & - & 0.0 & 0.0 \\
\hline & $\mathrm{L} \rightarrow \beta-\mathrm{Al}_{9} \mathrm{Fe}_{2} \mathrm{Si}_{2}+\alpha-\mathrm{Al}+\mathrm{L}$ & $559.6-554.8$ & 554.8 & 4.19 & 2.70 & - & - & 0.0 & 0.0 \\
\hline & $\mathrm{L} \rightarrow \beta-\mathrm{Al}_{9} \mathrm{Fe}_{2} \mathrm{Si}_{2}+\alpha-\mathrm{Al}+\mathrm{L}+\mathrm{Si}$ & $554.8-521.6$ & 521.6 & 61.30 & 3.67 & - & - & 7.18 & 0.0 \\
\hline & $\begin{array}{c}\beta-\mathrm{Al}_{9} \mathrm{Fe}_{2} \mathrm{Si}_{2}+\alpha-\mathrm{Al}+\mathrm{L}+\mathrm{Si} \rightarrow \\
\beta-\mathrm{Al}_{9} \mathrm{Fe}_{2} \mathrm{Si}_{2}+\alpha-\mathrm{Al}+\mathrm{Si}+\mathrm{Al}_{2} \mathrm{Cu}\end{array}$ & $521.6-521.5$ & 521.5 & 75.4 & 3.69 & - & - & 8.71 & 12.2 \\
\hline & $\beta-\mathrm{Al}_{9} \mathrm{Fe}_{2} \mathrm{Si}_{2}+\alpha-\mathrm{Al}+\mathrm{Si}+\mathrm{Al}_{2} \mathrm{Cu}$ & $521.5-20.0$ & 20 & 68.12 & 3.71 & - & - & 9.67 & 18.5 \\
\hline \multirow{6}{*}{$\mathrm{AlCu} 4 \mathrm{Si} 6 \mathrm{Fe} 2$} & $\mathrm{~L} \rightarrow \beta-\mathrm{Al}_{8} \mathrm{Fe}_{2} \mathrm{Si}+\mathrm{L}$ & $638.2-608.0$ & 608.0 & 0.0 & 0.0 & 2.19 & - & 0.0 & 0.0 \\
\hline & $\mathrm{L} \rightarrow \beta-\mathrm{Al}_{8} \mathrm{Fe}_{2} \mathrm{Si}+\alpha-\mathrm{Al}+\mathrm{L}$ & $608.0-603.5$ & 603.5 & 9.14 & 0.0 & 2.80 & - & 0.0 & 0.0 \\
\hline & $\mathrm{L} \rightarrow \beta-\mathrm{Al}_{9} \mathrm{Fe}_{2} \mathrm{Si}_{2}+\mathrm{L}+\alpha-\mathrm{Al}$ & $603.5-603.2$ & 603.2 & 12.19 & 3.63 & 0.0 & - & 0.0 & 0.0 \\
\hline & $\mathrm{L} \rightarrow \beta-\mathrm{Al}_{9} \mathrm{Fe}_{2} \mathrm{Si}_{2}+\mathrm{L}+\alpha-\mathrm{Al}$ & $603.2-558.8$ & 558.8 & 53.87 & 6.89 & 0.0 & - & 0.0 & 0.0 \\
\hline & $\mathrm{L} \rightarrow \beta-\mathrm{Al}_{9} \mathrm{Fe}_{2} \mathrm{Si}_{2}+\alpha-\mathrm{Al}+\mathrm{Si}$ & $558.8-523.8$ & 523.8 & 88.51 & 7.43 & 0.0 & - & 4.06 & 0.0 \\
\hline & $\begin{array}{c}\alpha-\mathrm{Al}+\beta-\mathrm{Al}_{9} \mathrm{Fe}_{2} \mathrm{Si}_{2}+\mathrm{Si} \rightarrow \alpha-\mathrm{Al}+ \\
\mathrm{Al}_{2} \mathrm{Cu}+\beta-\mathrm{Al}_{9} \mathrm{Fe}_{2} \mathrm{Si}_{2}+\mathrm{Si}\end{array}$ & 514.9-20.0 & 20 & 79.85 & 7.42 & 0.0 & - & 5.34 & 7.39 \\
\hline \multirow{4}{*}{$\mathrm{AlCu} 4 \mathrm{Si} 6 \mathrm{Mn} 2$} & $\mathrm{~L} \rightarrow \mathrm{Al}_{15} \mathrm{Si}_{2} \mathrm{Mn}_{4}+\mathrm{L}$ & $661.1-610.9$ & 610.9 & 0.0 & - & - & 3.43 & 0.0 & 0.0 \\
\hline & $\mathrm{L} \rightarrow \mathrm{Al}_{15} \mathrm{Si}_{2} \mathrm{Mn}_{4}+\alpha-\mathrm{Al}+\mathrm{L}$ & $610.9-560.2$ & 560.2 & 51.18 & - & - & 5.67 & 0.0 & 0.0 \\
\hline & $\mathrm{L} \rightarrow \mathrm{Al}_{15} \mathrm{Si}_{2} \mathrm{Mn}_{4}+\alpha-\mathrm{Al}+\mathrm{Si}$ & $560.2-522.6$ & 522.6 & 89.08 & - & - & 6.53 & 4.38 & 0.0 \\
\hline & $\begin{array}{c}\alpha-\mathrm{Al}+\mathrm{Al}_{15} \mathrm{Si}_{2} \mathrm{Mn}_{4}+\mathrm{Si} \rightarrow \alpha-\mathrm{Al}+ \\
\mathrm{Al}_{2} \mathrm{Cu}+\mathrm{Al}_{15} \mathrm{Si}_{2} \mathrm{Mn}_{4}+\mathrm{Si}\end{array}$ & $514.1-20.0$ & 20 & 80.43 & - & - & 6.69 & 5.48 & 7.40 \\
\hline
\end{tabular}




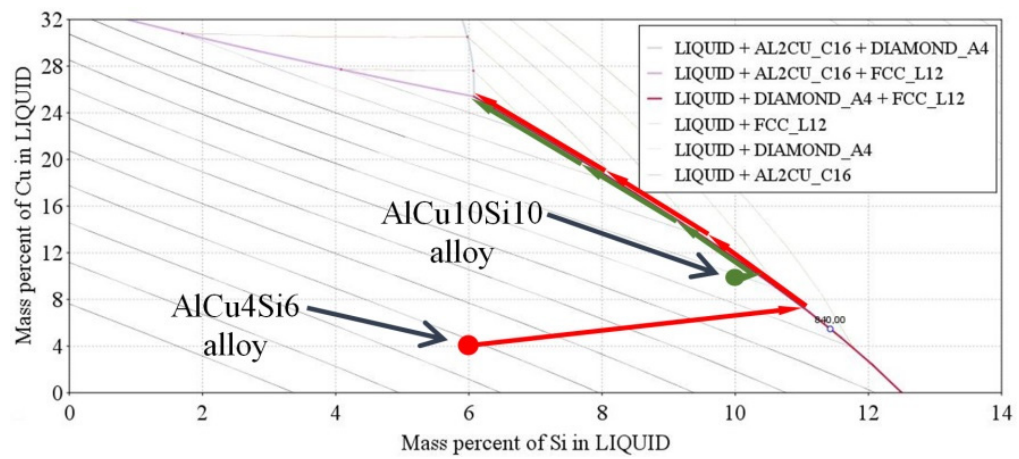

Figure 12. Ternary phase diagram-Al-Cu-Si system. Liquidus projection with the marked solidification path (Scheil-Gulliver solidification): red arrows represent the AlCu4Si6 alloy and green arrows represent AlCu10Si10.

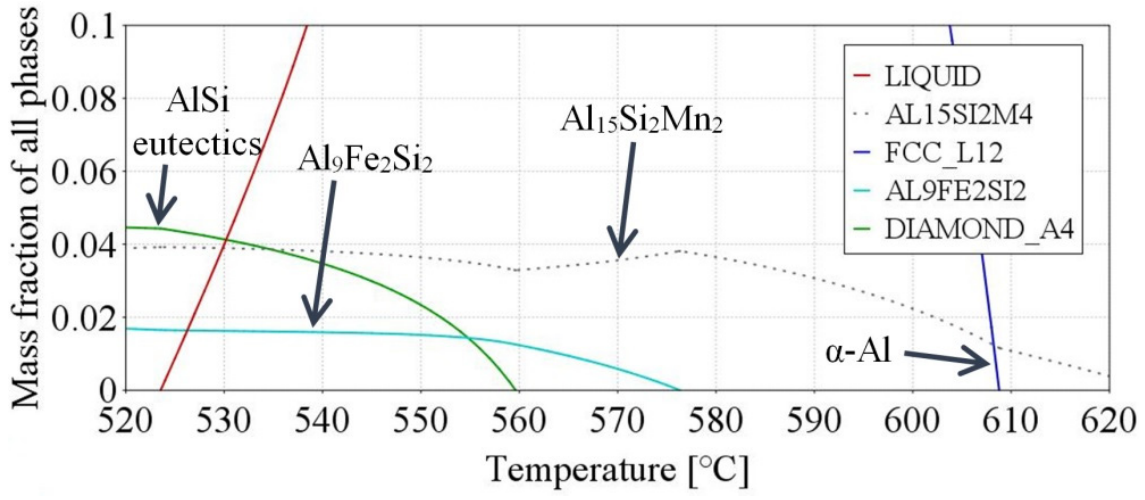

Figure 13. Property diagram for the AlCu4Si6Fe1.0Mn0.65 alloy.

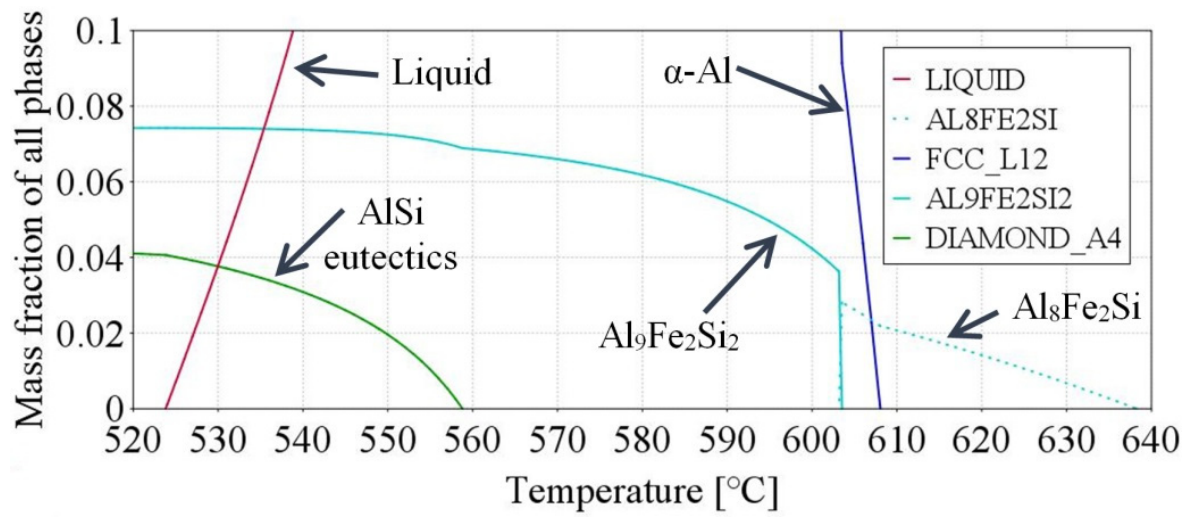

Figure 14. Property diagram for the AlCu4Si6Fe2.0 alloy.

On the basis of the binary Al-Cu phase diagram [2] and thermodynamic calculations (Table 2) [26], it can be concluded that for the AlCu4 alloy, the $\alpha$-Al phase will start to form at $649.8^{\circ} \mathrm{C}(\mathrm{L} \rightarrow \alpha-\mathrm{Al}+\mathrm{L})$ and solidification will finish at $571.6^{\circ} \mathrm{C}$ and for the mass fraction of $\alpha$ - $\mathrm{Al}$, dendrites will reach the value $\mathrm{f}_{\alpha-\mathrm{Al}}=100 \%$. At $506.6{ }^{\circ} \mathrm{C}$, the reaction $(\alpha-\mathrm{Al} \rightarrow \alpha-\mathrm{Al}$ $+\mathrm{Al}_{2} \mathrm{Cu}$ ) will start and the mass fraction of $\mathrm{Al}_{2} \mathrm{Cu}$ will reach the value of $\mathrm{f}_{\mathrm{Al} 2 \mathrm{Cu}}=7.40 \%$ at $20.0{ }^{\circ} \mathrm{C}$ and the mass fraction of $\alpha$-Al will reach $\mathrm{f}_{\alpha-\mathrm{Al}}=92.60 \%$.

On the basis of the ternary Al-Cu-Si phase diagram (Figure 12) [3,35] and thermodynamic calculations [26], it can be concluded that for the AlCu4Si6 alloy (Table 2): first $\alpha$-Al will form at $611.8{ }^{\circ} \mathrm{C}(\mathrm{L} \rightarrow \alpha-\mathrm{Al}+\mathrm{L})$, then the liquid will be enriched in Si and $\mathrm{Cu}$ to a concentration of $10.92 \% \mathrm{Si}$ and $7.36 \% \mathrm{Cu}$ until the eutectic reaction is reached at $562.9{ }^{\circ} \mathrm{C}$. Then, the eutectic groove $\mathrm{L} \rightarrow \mathrm{L}+\alpha-\mathrm{Al}+\mathrm{Si}$ starting at $562.9^{\circ} \mathrm{C}$ and ending at 
$526.3{ }^{\circ} \mathrm{C}$ with composition of rest liquid $6.10 \% \mathrm{Si}$ and $25.31 \% \mathrm{Cu}$, is followed by the final eutectic reaction $\mathrm{L} \rightarrow \alpha-\mathrm{Al}+\mathrm{Si}$. At this point (temperature $526.3^{\circ} \mathrm{C}$ ), the mass fraction of $\alpha$-Al reaches $\mathrm{f}_{\alpha-\mathrm{Al}}=94.98 \%$ and eutectics mass fraction reaches $\mathrm{f}_{\text {Eut }}=5.02 \%$. At $507.3{ }^{\circ} \mathrm{C}$ (Table 2), $\mathrm{Al}_{2} \mathrm{Cu}$ starts to form according to the reaction $\alpha-\mathrm{Al}+\mathrm{Si} \rightarrow \alpha-\mathrm{Al}+\mathrm{Al}_{2} \mathrm{Cu}+\mathrm{Si}$ and finally at $20{ }^{\circ} \mathrm{C}$, the mass fraction of $\alpha$-Al reaches $\mathrm{f}_{\alpha-\mathrm{Al}}=86.60 \%$, the mass fraction of $\mathrm{Al}_{2} \mathrm{Cu}$ reaches $\mathrm{f}_{\mathrm{Al} 2 \mathrm{Cu}}=7.40 \%$ and the mass fraction of the eutectic reaches $\mathrm{f}_{\text {Eut }}=6.00 \%$.

The AlCu4Si6Fe1.0Mn0.65 alloy starts to solidify (Figure 13, Table 2) with the $\mathrm{Al}_{15} \mathrm{Si}_{2} \mathrm{Mn}_{4}$ phase at $625.1{ }^{\circ} \mathrm{C}$ according to $\mathrm{L} \rightarrow \mathrm{L}+\mathrm{Al}_{15} \mathrm{Si}_{2} \mathrm{Mn}_{4}$, continuing to $608.8{ }^{\circ} \mathrm{C}$ where the mass fraction reaches $\mathrm{f}_{\mathrm{Al15Si2Mn} 4}=1.16 \%$. The second phase, $\alpha-\mathrm{Al}$, starts to form at $608.8{ }^{\circ} \mathrm{C}$ according to $\mathrm{L} \rightarrow \mathrm{L}+\mathrm{Al}_{15} \mathrm{Si}_{2} \mathrm{Mn}_{4}+\alpha-\mathrm{Al}$, and at $576.3{ }^{\circ} \mathrm{C}$ the mass fraction reaches $\mathrm{f}_{\alpha-\mathrm{Al}}=41.31 \%$ and $\mathrm{f}_{\mathrm{Al15Si2Mn} 4}=3.81 \%$. At $576.3^{\circ} \mathrm{C}$, the third phase, iron-rich intermetallic $\beta-\mathrm{Al}_{9} \mathrm{Fe}_{2} \mathrm{Si}_{2}$ begins to form according to the reaction $\mathrm{L} \rightarrow \alpha-\mathrm{Al}+\beta-\mathrm{Al}_{9} \mathrm{Fe}_{2} \mathrm{Si}_{2}+$ $\mathrm{Al}_{15} \mathrm{Si}_{2} \mathrm{Mn}_{4}$ and at $559.6{ }^{\circ} \mathrm{C}$ the mass fraction reaches $\mathrm{f}_{\alpha-\mathrm{Al}}=51.94 \%, \mathrm{f}_{\mathrm{Al} 15 \mathrm{Si} 2 \mathrm{Mn} 4}=3.29 \%$, $\mathrm{f}_{\beta \text {-Al9Fe2Si2 }}=1.25 \%$. Finally, the reaction $\mathrm{L} \rightarrow \alpha-\mathrm{Al}+\beta-\mathrm{Al}_{9} \mathrm{Fe}_{2} \mathrm{Si}_{2}+\mathrm{Al}_{15} \mathrm{Si}_{2} \mathrm{Mn}_{4}+\mathrm{Si}$ commences at $559.6{ }^{\circ} \mathrm{C}$ and finishes solidification at $523.5^{\circ} \mathrm{C}$ with mass fractions $\mathrm{f}_{\alpha-\mathrm{Al}}=90.00 \%$, $\mathrm{f}_{\mathrm{Al} 15 \mathrm{Si} 2 \mathrm{Mn} 4}=3.92 \%, \mathrm{f}_{\beta-\mathrm{Al} 9 \mathrm{Fe} 2 \mathrm{Si} 2}=1.65 \%$ and $\mathrm{f}_{\text {Eut }}=4.43 \%$. At $513.1^{\circ} \mathrm{C}($ Table 2 , Figure 13) $\mathrm{Al}_{2} \mathrm{Cu}$ starts to form according to the reaction $\alpha-\mathrm{Al}+\mathrm{Al}_{15} \mathrm{Si}_{2} \mathrm{Mn}_{4}+\beta-\mathrm{Al}_{9} \mathrm{Fe}_{2} \mathrm{Si}_{2}+\mathrm{Si} \rightarrow$ $\alpha-\mathrm{Al}+\mathrm{Al}_{2} \mathrm{Cu}+\mathrm{Al}_{15} \mathrm{Si}_{2} \mathrm{Mn}_{4}+\beta-\mathrm{Al}_{9} \mathrm{Fe}_{2} \mathrm{Si}_{2}+\mathrm{Si}$ and at $20{ }^{\circ} \mathrm{C}$, the mass fraction of the phases reaches the values $\mathrm{f}_{\alpha-\mathrm{Al}}=81.22 \%, \mathrm{f}_{\mathrm{Al} 2 \mathrm{Cu}}=7.40 \%, \mathrm{f}_{\mathrm{Al} 15 \mathrm{Si} 2 \mathrm{Mn}}=2.17 \%, \mathrm{f}_{\beta-\mathrm{A} 19 \mathrm{Fe} 2 \mathrm{Si} 2}=3.71 \%$ and $\mathrm{f}_{\text {Eut }}=5.50 \%$.

The AlCu4Si6Fe2.0 alloy starts to solidify (Figure 14, Table 2 ) with the $\beta-\mathrm{Al}_{8} \mathrm{Fe}_{2} \mathrm{Si}$ phase at $638.2{ }^{\circ} \mathrm{C}$ according to $\mathrm{L} \rightarrow \mathrm{L}+\beta-\mathrm{Al}_{8} \mathrm{Fe}{ }_{2} \mathrm{Si}$, continuing to $608.0^{\circ} \mathrm{C}$ where the mass fraction reaches $\mathrm{f}_{\beta-\mathrm{Al} 8 \mathrm{Fe} 2 \mathrm{Si}}=2.19 \%$. The second phase, $\alpha-\mathrm{Al}$, starts to form at $608.0^{\circ} \mathrm{C}$ according to $\mathrm{L} \rightarrow \mathrm{L}+\beta-\mathrm{Al}_{8} \mathrm{Fe}_{2} \mathrm{Si}+\alpha-\mathrm{Al}$, and at $603.5^{\circ} \mathrm{C}$ the mass fraction reaches $\mathrm{f}_{\alpha-\mathrm{Al}}=9.14 \%$ and $\mathrm{f}_{\beta-\mathrm{Al} 8 \mathrm{Fe} 2 \mathrm{Si}}=2.80 \%$. The third phase, $\beta-\mathrm{Al}_{9} \mathrm{Fe}_{2} \mathrm{Si}_{2}$, starts to precipitate at $603.5{ }^{\circ} \mathrm{C}$ according to reaction $\mathrm{L} \rightarrow \mathrm{L}+\mathrm{Al}_{9} \mathrm{Fe}_{2} \mathrm{Si}_{2}+\alpha$-Al and at $603.2{ }^{\circ} \mathrm{C}$ the mass fraction reaches $\mathrm{f}_{\alpha-\mathrm{Al}}=12.19 \%, \mathrm{f}_{\beta-\mathrm{Al} 8 \mathrm{Fe} 2 \mathrm{Si}}=0.0 \%, \mathrm{f}_{\beta-\mathrm{Al} 9 \mathrm{Fe} 2 \mathrm{Si} 2}=3.63 \%$, and phases continuing growth up to $558.8^{\circ} \mathrm{C}$ reach a mass fraction of $\mathrm{f}_{\alpha-\mathrm{Al}}=53.87 \%$ and $\mathrm{f}_{\beta-\mathrm{Al} 9 \mathrm{Fe} 2 \mathrm{Si} 2}=6.89 \%$. Finally, the reaction $\mathrm{L} \rightarrow \alpha-\mathrm{Al}+\beta-\mathrm{Al}_{9} \mathrm{Fe}_{2} \mathrm{Si}_{2}+\mathrm{Si}$ starts at $558.8{ }^{\circ} \mathrm{C}$ and completes the solidification at $523.8^{\circ} \mathrm{C}$ with mass fractions $\mathrm{f}_{\alpha-\mathrm{Al}}=88.51 \%, \mathrm{f}_{\beta-\mathrm{Al} 9 \mathrm{Fe} 2 \mathrm{Si} 2}=7.43 \%$ and $\mathrm{f}_{\text {Eut }}=4.06 \%$. At $514.9{ }^{\circ} \mathrm{C}$ (Table 2, Figure 14), $\mathrm{Al}_{2} \mathrm{Cu}$ starts to form according to the reaction $\alpha-\mathrm{Al}+\beta-\mathrm{Al}_{9} \mathrm{Fe}_{2} \mathrm{Si}_{2}+\mathrm{Si}$ $\rightarrow \alpha-\mathrm{Al}+\mathrm{Al}_{2} \mathrm{Cu}+\beta-\mathrm{Al}_{9} \mathrm{Fe}_{2} \mathrm{Si}_{2}+\mathrm{Si}$ and at $20{ }^{\circ} \mathrm{C}$, the mass fraction reaches $\mathrm{f}_{\alpha-\mathrm{Al}}=79.85 \%$, $\mathrm{f}_{\mathrm{Al} 2 \mathrm{Cu}}=7.39 \%, \mathrm{f}_{\beta-\mathrm{Al} 9 \mathrm{Fe} 2 \mathrm{Si} 2}=7.42 \%$ and $\mathrm{f}_{\text {Eut }}=5.34 \%$.

\section{Discussion}

The microstructure changes due to forced flow need to be discussed, especially the transformation from a dendritic structure to rosettes with minor dendrites and occasionally, to spheroids, as extensively mentioned in the introductory paragraph. Here, the measured parameters (specific surface, dendrite arm spacing, number density, length of intermetallics, and eutectic spacing) and the various effects of stirring on the growing phases and alloys studied will be discussed and analyzed in comparison with literature data.

\subsection{Rosettes}

In the resultant microstructure $\alpha$-Al crystals formed as rosettes, fully shaped dendrites, and some globular grains can be observed. In the present study, rosettes also appear to be the ripened arms of deformed dendritic crystals, and build up as a result of rotation of the dendrite tip during growth. The fact that many dendrites were found in addition to overwhelming rosettes supports the explanation mentioned in the Introduction.

\subsection{Spheroids}

The formation of spheroids requires a very high shear rate produced by intense stirring [30], and this was not achieved in the present experiment, where the rotational speed of melt in the cylindrical shaped specimen was estimated to be $2.1 \mathrm{~s}^{-1}$, so the observed spheroidal forms seem to be part of dendrites. 


\subsection{Dendrites}

In the equiaxed solidification experiments to date (Table 1), with increasing flow, the secondary spacing $\lambda_{2}$ decreased from 232 to $145 \mu \mathrm{m}(-37 \%)$ for the AlCu 4 base alloy. Moreover, for the other alloys, $\lambda_{2}$ decreased with changes in $\lambda_{2}$ ranging between $-5 \%$ and $-20 \%$. Only for the AlCu4Si6Fe1 alloy, the secondary spacing $\lambda_{2}$ remained almost unchanged; $79 \mu \mathrm{m}$ for solidification without stirring and $80 \mu \mathrm{m}$ for stirring.

Stirring shortened the solidification time (Table 1) and this, according to Equation (1) for $\lambda_{2}$, should mean a decrease in the secondary spacing $\lambda_{2}$. Smaller secondary spacing was measured for almost all the alloys, except for AlCu4Si6Fe1 and AlCu4Si6Fe2, where a nondendritic structure was formed. For the AlCu4 alloy solidified without stirring $\lambda_{2}=232 \mu \mathrm{m}$, but with flow, based on the measured solidification time, the calculated secondary spacing $\left(\lambda_{2}=221 \mu \mathrm{m}\right)$ is still larger than the measured one $\left(\lambda_{2}=145 \mu \mathrm{m}\right)$. In order to reach the measured value of $145 \mu \mathrm{m}$, the exponent $\mathrm{n}_{1}$ in Equation (1) should be lower, even lower than $\mathrm{n}_{1}$ for diffusive ripening (without stirring) [44]. This means a decrease from 0.330 to 0.261 , which is contrary to literature data $[44,50]$ suggesting an increase in $\mathrm{n}_{1}$ caused by convective ripening. For other alloys (except $\mathrm{AlCu} 4 \mathrm{Si} i \mathrm{Fe} 1$ and $\mathrm{AlCu} 4 \mathrm{Si} 6 \mathrm{Fe} 2$ ), according to Equation (1), a shorter solidification time determines a smaller secondary spacing $\lambda_{2}$. In order to achieve the calculated $\lambda_{2}$ values as measured, the exponent by stirring should be lower, decreasing from 0.33 for diffusive mass transport to a range between 0.301 and 0.328 for convective ripening, and this is much less than the $0.47-0.50$ found in the literature $[44,50]$ for directional solidification. The behavior of the exponents suggests the lack of forced convection by electromagnetic stirring for the alloys, or its significant reduction during the coarsening of secondary arms. By predominant rosettes and the rarely occurring dendrites in stirred specimens, the fact that dendrites actually were formed implies that the flow was very small in these small areas, and that the secondary spacing should be considered to have formed only under diffusive rather than convective conditions. The fact that the results for $\lambda_{2}$ and $n_{1}$ are in contrast to [44,50], where the secondary spacing $\lambda_{2}$ increased considerably under the influence of flow by directional solidification, also supports the concept of local-only diffusive conditions, or too-little convection, to determine the shape of dendrites. The effect of flow on $\lambda_{2}$ and $n_{1}$ under directional solidification $[44,50]$ and equiaxed solidification conditions should be considered independently, as presented by current results.

In the study by [54], the specific surface $S_{\mathrm{v}}$ was found to be in the range $0.04-0.22 \mu \mathrm{m}^{-1}$ for holding times from 20 to $500 \mathrm{~min}$, by mushy zone coarsening for the AlCu30 alloy. Kasperovich and Genau [54] found a decrease from 0.077 to $0.035 \mu \mathrm{m}^{-1}$ with increasing electromagnetic stirring generated by the $6 \mathrm{mT}$ rotating magnetic field (RMF), for a holding time of $200 \mathrm{~min}$.

For almost all alloys studied here, $S_{\mathrm{V}}$ decreased under fluid flow, meaning that the dendrites or rosettes are more oval under stirring. Smaller $S_{\mathrm{v}}$ also means larger structures or shapes, which could be well observed based on the example of a circle. It suffices to mention only that the circle's $S_{v}$ for $1 \mu \mathrm{m}$ radius is $2 \mu \mathrm{m}^{-1}$, whilst for a radius of $10 \mu \mathrm{m}$ it is $0.2 \mu \mathrm{m}^{-1}$. The decrease in $S_{v}$ caused by stirring ranges is between $-23 \%$ and $-41 \%$ (Table 1). For the calculation of $S_{v}$, based on Equation (3) and the measured solidification time, a coefficient should be applied in the equation, the values of which are in the range between 133 and 298 for solidification without stirring and between 116 and 478 for stirring, for the studied alloys. The calculation of $S_{v}$ based on the solidification time requires, in Equation (3), the introduction and determination of the exact coefficient.

\subsection{Eutectics}

Table 1 shows that for AlCu4Si6, forced convection decreases the eutectic spacing $\lambda_{\mathrm{E}}$ by about $2 \%$-from $39 \mu \mathrm{m}$ to $38 \mu \mathrm{m}$ - and, with a standard deviation of 4.7 and $3.9 \mu \mathrm{m}$, these changes appear negligible. For AlCu4Si6Fe2.0, forced convection increases the eutectic spacing $\lambda_{\mathrm{E}}$ by about $32 \%$-from 14.6 to $19.3 \mu \mathrm{m}$-and the standard deviation is 1.8 and $2.3 \mu \mathrm{m}$. For the other alloys, the change in spacing is similar, however, not only decreases, 
but also increases are present, and with a similar standard deviation, some changes appear negligible. When the standard deviation is ignored, for alloys with Fe we have an increase in the eutectic spacing, whilst for alloys containing $\mathrm{Mn}$, flow reduces the spacing. It seems that some influence of both elements on the growing phases may cause such an effect. The unclear effect of stirring on the eutectic spacing may be due to the small amount of this phase, $6.0 \mathrm{wt} . \%$ [35] in the AlCu4Si6 and $5.34 \mathrm{wt} . \%$ in the AlCu4Si6Fe2.0 alloy, and the irregular formations of AlSi eutectics. In the AlCu10Si10 alloy, where AlSi eutectics start to form at $556.9^{\circ} \mathrm{C}$ almost at the beginning $\left(560.7^{\circ} \mathrm{C}\right)$ of solidification and continue almost throughout the solidification period up to $521.6^{\circ} \mathrm{C}$, the increase is greater than in other alloys as the eutectics form at the end of solidification. Finally, the results suggest, that because eutectics grow massively at the end of solidification, when presumably rosettes and dendrites form a stationary and rigid structure, flow is only possible in the interdendritic area with a significantly reduced velocity. The electromagnetic field still present in the material, in the small interdendritic region, generates too little flow for significant changes in the eutectic spacing.

Table 1 shows clearly that for binary eutectics $\mathrm{Al}_{2} \mathrm{Cu}$ in the $\mathrm{AlCu} 4$ alloy, forced convection decreases the eutectic spacing $\lambda_{\mathrm{E}}$ by about $10 \%$-from $2.53 \mu \mathrm{m}$ to $2.27 \mu \mathrm{m}$-and with standard deviation values of $0.2 \mu \mathrm{m}$ and $0.2 \mu \mathrm{m}$, the changes are small. For AlCu4Si6, forced convection increases the eutectic spacing $\lambda_{\mathrm{E}}$ by about $52 \%$ from $5.27 \mu \mathrm{m}$ to $8.05 \mu \mathrm{m}$ and the standard deviation is $0.5 \mu \mathrm{m}$ and $1.5 \mu \mathrm{m}$. The results are similar for other alloys. When the standard deviation is not taken into account, for alloys with Mn we have an increase in eutectic spacing. Binary $\mathrm{Al}_{2} \mathrm{Cu}$ phases also seem to be affected by convection, which causes changes of about $10-50 \%$ in the $\lambda_{\mathrm{Al} 2 \mathrm{Cu}}$ spacing. However, the direction is unclear. There are no literature data concerning the effect of fluid flow on $\mathrm{Al}_{2} \mathrm{Cu}$ phases.

The unclear effect of convection on AlSi eutectics and $\mathrm{Al}_{2} \mathrm{Cu}$ in bulk solidification in contrast to directional solidification requires further investigation on a smaller scale, including morphology of eutectic cells and the application of a stronger electromagnetic field, far from the currently used $11 \mathrm{mT}$.

\subsection{Intermetallics}

The $\beta$ phase shortening currently observed is about 33\% (Table 1) for the AlCu4Si6Fe1 alloy. The decreasing average length is consistent with the results of [59-61,63]. For the AlSi5Fe1 alloy [59], the changes are $-20 \%$ in a similar bulk solidification, whilst currently for $\mathrm{AlCu} 4 \mathrm{Si} 6 \mathrm{Fe} 1$ alloys, the flow decreased $\mathrm{L}_{\beta}$ by about $33 \%$. For $\mathrm{AlCu} 4 \mathrm{Si} 6 \mathrm{Fe} 1 \mathrm{Mn} 0.65$, the flow reduced the $L_{\beta}$ of the $\beta$ phases by only $6 \%$. The opposite situation occurred for the $\mathrm{AlCu} 10 \mathrm{Si10Fe} 1$ and $\mathrm{AlCu} 4 \mathrm{Si6} \mathrm{Fe} 2$ alloys, where forced convection caused an increase in the average length of $\beta$ by $23 \%$ and $76 \%$, respectively. From the precipitation sequence (Table 2 ), it is known that for the AlCu4Si6Fe1 alloy, the $\beta$ phases start to grow as a second phase trough massively grows the $\alpha$-Al phase, and the trough is a pronounced dendritic or rosette structure. For the AlCu10Si10Fe1.0 alloy (Table 2), the $\beta$ phases start to grow as the first phase before the $\alpha$-Al phase, between temperatures of $560-610^{\circ} \mathrm{C}$; about half the amount of the Fe-rich phases precipitated. For the AlCu4Si6Fe2.0 alloy (Figure 14), the $\beta$ phases start to grow as the first phase before the $\alpha$-Al phase, between temperatures of $608-638^{\circ} \mathrm{C}$; about $30 \%$ of the amount of Fe-rich phases precipitated. For both AlCu10Si10Fe1.0 and $\mathrm{AlCu} 4 \mathrm{Si} 6 \mathrm{Fe} 2.0$ alloys, the increase in $\beta$ length occurred, when the $\beta$ phases start to grow as the first phase in liquid metal and this occurred without disturbing the solid phases, and intensive stirring was not inhibited by any other precipitates. The novelty is that $\beta$ phases grow longer under stirring.

Analysis of the stirring effect in directional solidification of AlSiFe alloys [63] has indicated the shortening of $\beta$ phases has the complex effect of forced convection, solute segregation, dendrites and intermetallics morphology. Fragmentation and partial dissolution of $\beta-\mathrm{Al}_{5} \mathrm{FeSi}$ acting as nucleation sites were used as an explanation for the cause of the higher number density $n_{\beta}$ and reduced $\beta$ platelet length $L_{\beta}$. However, similarly, for alloys such as AlCu10Si10Fe1.0 and AlCu4Si6Fe2.0, it should be mentioned that with intense 
forced convection, in the presence of only $\beta$ phases in liquid alloys without any other precipitates, there are good conditions for growth of large $\beta$. The change of $\beta$ platelets in the flowing melt is probably caused by the rotation of the solid particle and elimination of the constitutional undercooling trough reduction of thermal and solutal diffusion layers at the solid-liquid interface.

\subsection{Solidification by Stirring}

For the AlCu4 alloy (Table 1), stirring reduced the secondary spacing $\lambda_{2}$ from 232 to $145 \mu \mathrm{m}(-37 \%)$, changed $\mathrm{S}_{\mathrm{v}}$ from 0.027 to $0.016 \mu \mathrm{m}^{-1}$, and reduced the eutectic spacing from 2.53 to $2.27 \mu \mathrm{m}$. According to thermodynamic calculations (Table 2), $\alpha$-Al starts to form first at $649.8{ }^{\circ} \mathrm{C}$, and solidification ends at $571.6^{\circ} \mathrm{C}$ and $\mathrm{Al}_{2} \mathrm{Cu}$ starts to precipitate at $506.6^{\circ} \mathrm{C}$. Flow determined the growth of $\alpha-\mathrm{Al}$, causing the formation of rosettes (Figure 2), minor dendrites and occasionally spheroids, and significantly changed the secondary spacing $\lambda_{2}$ and specific surface. Convection appears to have no effect on $\mathrm{Al}_{2} \mathrm{Cu}$ precipitation below solidus temperature and, vice versa, $\mathrm{Al}_{2} \mathrm{Cu}$ do not determine the forced flow, suggesting changes in the $\mathrm{Al}_{2} \mathrm{Cu}$ eutectic spacing $\lambda_{\mathrm{Al} 2 \mathrm{Cu}}$ are the result of measurement error or other causes.

For the AlCu4Si6 alloy (Table 1) stirring produced changes in the measured $\lambda_{2}$ from 99 to $88 \mu \mathrm{m}-11 \%$ ), a decrease in $\mathrm{S}_{\mathrm{v}}$ from 0.044 to $0.027 \mu \mathrm{m}^{-1}$ and AlSi eutectic spacing from 39 to $38 \mu \mathrm{m}$, and an increase in the $\mathrm{Al}_{2} \mathrm{Cu}$ spacing from 5.72 to $8.05 \mu \mathrm{m}$. According to Figure 12 and Table 2, $\alpha$-Al starts to form first at $611.8^{\circ} \mathrm{C}$, followed by the AlSi eutectics at $562.9^{\circ} \mathrm{C}$. Finally, solidification ends at $526.3^{\circ} \mathrm{C}$ and $\mathrm{Al}_{2} \mathrm{Cu}$ starts to precipitate at $507.3^{\circ} \mathrm{C}$. The growth of $\alpha-\mathrm{Al}$ appears to be undisturbed by other phases and allowed for the rosette formation (Figure 3). AlSi eutectics started to form in the middle of temperature range $\mathrm{T}_{\text {liq }}$ $\mathrm{T}_{\text {sol }}\left(562.9^{\circ} \mathrm{C}\right.$, Table 2), but changes in eutectic spacing $\lambda_{\text {Eut }}$ are negligible. In comparison to the AlCu4 alloy, the decrease in $\lambda_{2}$ is smaller, which is probably due to the flow diminished by the occurrence of AlSi eutectics. Moreover, for this alloy, convection seems to have no effect on $\mathrm{Al}_{2} \mathrm{Cu}$ precipitation below the solidus temperature, suggesting changes in the $\mathrm{Al}_{2} \mathrm{Cu}$ eutectic spacing $\lambda_{\mathrm{Al} 2 \mathrm{Cu}}$ can contribute to measurement error or other causes.

For the AlCu4Si6Fe1 alloy (Table 1), forced convection modified $\lambda_{2}$ only in the range between 79 and $80 \mu \mathrm{m}(+1 \%)$, reduced $S_{v}$ from 0.050 to $0.032 \mu \mathrm{m}^{-1}$, shortened the $\beta-\mathrm{Al}_{5} \mathrm{FeSi}$ phases from 115 to $77 \mu \mathrm{m}$, increased the eutectic spacing $\lambda_{\text {Eut }}$ from 12.4 to $14.3 \mu \mathrm{m}$ and changed the $\lambda_{\mathrm{Al} 2 \mathrm{Cu}}$ spacing from 9.07 to $7.45 \mu \mathrm{m}$. According to thermodynamic calculations (Table 2), $\alpha$-Al starts to form first at $608.9^{\circ} \mathrm{C}$, then the $\beta-\mathrm{Al}_{5} \mathrm{FeSi}$ phase at $601.1^{\circ} \mathrm{C}$, and then the AlSi eutectics at $560.4{ }^{\circ} \mathrm{C}$. Solidification ends at $525.0^{\circ} \mathrm{C}$ and $\mathrm{Al}_{2} \mathrm{Cu}$ starts to form at $511.1^{\circ} \mathrm{C}$. The growth of $\alpha$ - $\mathrm{Al}$ and forced flow appear to be undisturbed by $\beta-\mathrm{Al}_{5} \mathrm{FeSi}$ up to $601.1^{\circ} \mathrm{C}$ and by AlSi up to $560.4{ }^{\circ} \mathrm{C}$, and consequently $\alpha$-Al rosettes formed (Figure 6) instead of dendrites, but $\lambda_{2}$ changed only weakly. The $33 \%$ shortening of the $\beta-\mathrm{Al}_{5} \mathrm{FeSi}$ phases caused by flow and an increase in number density $n_{\beta}(59 \%)$ (Table 1$)$ seem to be affected from the beginning by the presence of $\alpha$-Al and from the middle of the $\mathrm{T}_{\text {liq }}-\mathrm{T}_{\text {sol }}$ solidification range by the AlSi eutectics. $\beta$ phases start to grow when $\alpha-\mathrm{Al}$ is formed at $13 \%$ (Table 2), and by the middle of the solidification range the amount of $\alpha-\mathrm{Al}$ is about $50 \%$. The shortening of $\beta$ and increase in number density occur between at least $50 \%$ grown dendrites, which supports a mechanical interaction between $\alpha$-Al dendrites and moving $\beta$. At temperatures close to solidus, the precipitated $\alpha-\mathrm{Al}, \beta-\mathrm{Al}_{5} \mathrm{FeSi}$ and AlSi eutectic, probably reduced flow and convective ripening whilst supporting diffusive mass transport, so the secondary dendrite spacing $\lambda_{2}$ stayed almost unchanged and a small increase in eutectic spacing $\lambda_{\mathrm{E}}$ was observed. Moreover, for this alloy, convection seems to have an effect on $\mathrm{Al}_{2} \mathrm{Cu}$.

For the AlCu4Si6Mn0.65 alloy (Table 1), melt flow modified $\lambda_{2}$ from 100 to $80 \mu \mathrm{m}$ $(-20 \%)$, reduced $\mathrm{S}_{\mathrm{v}}$ from 0.043 to $0.032 \mu \mathrm{m}^{-1}$, decreased the eutectic spacing $\lambda_{\text {Eut }}$ from 32.7 to $30.5 \mu \mathrm{m}$ and changed the $\lambda_{\mathrm{Al} 2 \mathrm{Cu}}$ spacing from 5.87 to $6.62 \mu \mathrm{m}$. For Mn-rich phases (Figure 7), the flow reduced the average overall dimension by about $42 \%$, from 189 to $109 \mu \mathrm{m}$ and increased the number density $\mathrm{n}_{\mathrm{Mn}}$ from 0.17 to $0.26 \mathrm{~mm}^{-2}$. According to 
thermodynamic calculations (Table 2), first $\alpha$-Al starts to form at $610.9{ }^{\circ} \mathrm{C}$, then $\mathrm{Al}_{15} \mathrm{Si}_{2} \mathrm{Mn}_{4}$ phase at the $593.6^{\circ} \mathrm{C}$, and the AlSi eutectics at the $561.5^{\circ} \mathrm{C}$. Solidification ends at $524.1{ }^{\circ} \mathrm{C}$ and at $509.4{ }^{\circ} \mathrm{C} \mathrm{Al}_{2} \mathrm{Cu}$ starts to form. Precipitation of $\alpha$-Al appears to be undisturbed by $\mathrm{Mn}$-phases and by AlSi, and rosettes are formed, dendrite spacing $\lambda_{2}$ changes and smaller $\mathrm{Mn}$-phases occur. In view of the observed changes in characteristic parameters for $\alpha-\mathrm{Al}, \mathrm{Mn}$ phases and AlSi eutectics, the forced flow seems to be undisturbed or slightly diminished by precipitating phases. For AlCu4Si6Mn0.65 and AlCu4Si6 alloys, in comparison to $\mathrm{AlCu} 4 \mathrm{Si}$ Fe1, changes in $\lambda_{2}$ are stronger, so the flow diminishing effect of Mn-phases is smaller than by $\beta$ platelets. $\mathrm{Al}_{2} \mathrm{Cu}$ seems not to affect the flow nor is it itself determined by forced convection.

For the AlCu4Si6Fe1Mn0.65 alloy (Table 1), intensive stirring modified $\lambda_{2}$ from 85 to $79 \mu \mathrm{m}(-7 \%)$, reduced $S_{\mathrm{V}}$ from 0.047 to $0.036 \mu \mathrm{m}^{-1}$, reduced the eutectic spacing $\lambda_{\text {Eut }}$ from 14.3 to $13.2 \mu \mathrm{m}$ and changed the $\lambda_{\mathrm{Al} 2 \mathrm{Cu}}$ spacing from 8.41 to $8.59 \mu \mathrm{m}$. For Fe-rich phases the flow decreased the average length by about $6 \%$, from 80 to $75 \mu \mathrm{m}$ and increased the number density $\mathrm{n}_{\mathrm{Mn}}$ from 21 to $69 \mathrm{~mm}^{-2}$ and for Mn-rich phases, the average overall dimension changed by about $3 \%$, from 315 to $323 \mu \mathrm{m}$ and reduced number density $\mathrm{n}_{\mathrm{Mn}}$ from 0.18 to $0.08 \mathrm{~mm}^{-2}$. According to thermodynamic calculations (Figure 13), the $\mathrm{Al}_{15} \mathrm{Si}_{2} \mathrm{Mn}_{4}$ phase starts to form first at $625.1^{\circ} \mathrm{C}, \alpha$-Al forms straight after at $608.8^{\circ} \mathrm{C}$, then iron-rich intermetallic phase at $576.3^{\circ} \mathrm{C}$, and then AlSi eutectics at $559.6{ }^{\circ} \mathrm{C}$. Solidification ends at $523.5^{\circ} \mathrm{C}$, and, at $513.1{ }^{\circ} \mathrm{C}$, it starts to form $\mathrm{Al}_{2} \mathrm{Cu}$. Stirring resulted in the growth of $\alpha-\mathrm{Al}$ rosettes, $\beta$ platelets and Mn-phases with only slightly modified length $\mathrm{L}_{\beta}$ and dimension $\mathrm{L}_{\mathrm{Mn}} \cdot \mathrm{Al}_{15} \mathrm{Si}_{2} \mathrm{Mn}_{4}$ phases growing before and similar to $\alpha$-Al influenced forced convection weakly in the early stage of solidification, and flow caused formation of rosettes. Due to the common occurrence of Fe- and Mn-phases, in the later stage of solidification, the effect of forced flow on the changes in dimensions of both phases and the modification of secondary dendrite spacing $\lambda_{2}$ is insignificant; it is probable that both phases reduce convection. In comparison to AlCu4Si6Fe1 and AlCu4Si6Mn0.65 alloys, presence of Fe and Mn elements results in a smaller average length of iron-rich phases and larger Mn-phases, because measuring and counting $\mathrm{Mn}$-phases means consideration of $\mathrm{Al}_{15}(\mathrm{FeMn})_{3} \mathrm{Si}_{2}$ and $\mathrm{Al}_{12}(\mathrm{FeMn})_{3} \mathrm{Si}$ precipitates.

For the AlCu10Si10 alloy (Table 1), forced flow resulted in changes in the measured $\lambda_{2}$ from 56 to $53 \mu \mathrm{m}$ ( $-5 \%$ ), a decrease in $S_{\mathrm{V}}$ from 0.066 to $0.043 \mu \mathrm{m}^{-1}$ and an increase in the AlSi eutectic spacing from 24.1 to $29.7 \mu \mathrm{m}$ and a decrease in the $\mathrm{Al}_{2} \mathrm{Cu}$ spacing from 13.2 to $12.38 \mu \mathrm{m}$. According to Table 2 and Figure 12, $\alpha$-Al starts to form first at $560.7^{\circ} \mathrm{C}$ and then AlSi eutectics at $556.9^{\circ} \mathrm{C}$. Finally, solidification ends at $521.6^{\circ} \mathrm{C}$ and $\mathrm{Al}_{2} \mathrm{Cu}$ starts to precipitate at $521.6^{\circ} \mathrm{C}$. The growth of $\alpha$-Al seems to be undisturbed by other phases and allows for the formation of rosettes under stirring conditions, whilst dendrites spacing decreases only $5 \%$, so the flow seems to be reduced in the late stage of solidification. AlSi eutectics started to form almost similarly to $\alpha$-Al and clearly under the influence of stirring, as spacing increased by $23 \%$.

For the AlCu10Si10Fe1 alloy (Table 1), melt stirring modified $\lambda_{2}$ from 66 to $57 \mu \mathrm{m}$ $(-13 \%), S_{\mathrm{v}}$ from 0.047 to $0.071 \mu \mathrm{m}^{-1}(+51 \%)$, increased the eutectic spacing $\lambda_{\text {Eut }}$ from 17.5 to $18.9 \mu \mathrm{m}(8 \%)$ and changed the $\lambda_{\mathrm{Al} 2 \mathrm{Cu}}$ spacing from 13.08 to $15.38 \mu \mathrm{m}$. For Fe-rich phases (Figure 8), the flow increased the average length $\mathrm{L}_{\beta}$ by about $23 \%$, from 524 to $642 \mu \mathrm{m}$ and decreased the number density $\mathrm{n}_{\beta}$ from 4.2 to $3.7 \mathrm{~mm}^{-2}$. According to thermodynamic calculations (Table 2), the $\beta$ phase starts to precipitate at $610.0{ }^{\circ} \mathrm{C}$, then $\alpha$-Al phase at $559.6{ }^{\circ} \mathrm{C}$ and then AlSi eutectics at $554.8^{\circ} \mathrm{C}$. Solidification ends at $521.6^{\circ} \mathrm{C}$ and just below this temperature, $\mathrm{Al}_{2} \mathrm{Cu}$ starts to form. When the $\alpha$-Al phase starts to grow at $559.6^{\circ} \mathrm{C}$ (Table 2), the $\beta$ phases have reached a mass fraction of $\mathrm{f}_{\beta-\mathrm{Al}} \mathrm{Fe} 2 \mathrm{Si} 2=2.51 \%$ and by the end of solidification $\mathrm{f}_{\beta \text {-Al9Fe2Si2 }}=3.69 \%$, which means that about $68 \%$ of $\beta$ (or rather $68 \%$ of the Fe content) precipitates in a completely liquid alloy without any other solid phases. In the liquid alloy, precipitating as the first iron rich phase seems to have good conditions to reach large dimensions, and this tendency is aided by forced flow, causing an increase in the length $L_{\beta}$ by decreasing number density $n_{\beta}$. Intense movement of $\beta$ in the fully liquid 
alloy favors its growth. The $\beta$ platelets formed do not disrupt the stirring and precipitation of $\alpha-\mathrm{Al}$ as rosettes may occur. Through some occurring dendrites, the spacing is reduced and the AlSi eutectic spacing increases.

For the AlCu4Si6Fe2 alloy (Table 1), forced convection modified the specific surface $\mathrm{S}_{\mathrm{v}}$ from 0.056 to $0.041 \mu \mathrm{m}^{-1}(-27 \%)$, increased the eutectic spacing $\lambda_{\text {Eut }}$ from 14.6 to $19.3 \mu \mathrm{m}$ $(8 \%)$ and changed the $\lambda_{\mathrm{Al} 2 \mathrm{Cu}}$ spacing from 6.04 to $7.92 \mu \mathrm{m}$. For the Fe-rich phases, the flow caused an increase in the average length by about $76 \%$, from 66 to $116 \mu \mathrm{m}$, and a decrease in the number density $n_{\beta}$ from 303 to $87 \mathrm{~mm}^{-2}$. According to the property diagram (Figure 14) and thermodynamic calculations (Table 2), the $\beta-\mathrm{Al}_{8} \mathrm{Fe}_{2} \mathrm{Si}$ phase starts to precipitate as the first at $638.2^{\circ} \mathrm{C}$, the $\alpha$-Al phase does this as the second one at $608.0^{\circ} \mathrm{C}$, $\beta-\mathrm{Al}_{9} \mathrm{Fe}_{2} \mathrm{Si}_{2}$ as the third at $603.5^{\circ} \mathrm{C}$ and finally AlSi eutectics starts to grow at $558.8^{\circ} \mathrm{C}$ and ends solidification at $523.8^{\circ} \mathrm{C}$. At $514.9^{\circ} \mathrm{C}, \mathrm{Al}_{2} \mathrm{Cu}$ starts to form. When the $\alpha$-Al phase starts to grow at $608.0^{\circ} \mathrm{C}$, the $\beta$ phases reach $\mathrm{f}_{\beta-\mathrm{Al}} \mathrm{AFe} 2 \mathrm{Si}=2.19 \%$ and at the end of solidification $\mathrm{f}_{\beta-\mathrm{Al} \text { Fe } 2 \mathrm{Si} 2}=7.43 \%$, which means that about $29 \%$ of $\beta$ (or rather $29 \%$ of the Fe content) precipitates in a completely liquid alloy without any other solid phases, and the rest of $\beta$ grows due to the presence of $\alpha-\mathrm{Al}$ and AlSi eutectics. The temperature range of $30.2{ }^{\circ} \mathrm{C}$ (before the precipitation of $\alpha-\mathrm{Al}$ ) for the growth of iron-rich phases in the AlCu4Si6Fe2.0 (by $2 \% \mathrm{Fe}$ ) alloy causes the growth of smaller phases in comparison to the temperature range of $50.4{ }^{\circ} \mathrm{C}$ in $\mathrm{AlCu} 10 \mathrm{Si10} \mathrm{Fe} 1.0$ (by $1 \% \mathrm{Fe}$ ). In the liquid alloy, the iron rich phase precipitating at first (Figures 9 and 10a) appears to have the suitable conditions to grow and at $2 \mathrm{wt} . \% \mathrm{Fe}$, the iron phases reach a high number density owing to the measured large number of phases; 3990 for solidification without and 1146 with stirring. Forced flow causes an increase in the average length $\mathrm{L}_{\beta}$, similar to that in the AlCu10Si10Fe1 alloy and opposite to that in $\mathrm{AlCu} 4 \mathrm{Si} 6 \mathrm{Fe} 1$, and the growth of $\beta$ as the first phase in the completely liquid alloy should be responsible for this. In the alloy, a non-dendritic $\alpha$-Al structure occurred and its growth seems to be associated with an increase in $\beta$ (Figure 9), suggesting inoculation and growth between and on $\beta$ phases.

For the AlCu4Si6Mn2 alloy (Table 1), melt flow modified $\lambda_{2}$ from 94 to $85 \mu \mathrm{m}(-9 \%)$, reduced the specific surface $S_{\mathrm{v}}$ from 0.036 to $0.026 \mu \mathrm{m}^{-1}(-28 \%)$, reduced the eutectic spacing $\lambda_{\text {Eut }}$ from 29.5 to $26.3 \mu \mathrm{m}(-10.8 \%)$ and changed the $\lambda_{\mathrm{Al} 2 \mathrm{Cu}}$ spacing from 7.90 to $9.55 \mu \mathrm{m}$. For the Mn-rich phases, the flow reduced the average overall dimension $\mathrm{L}_{\mathrm{Mn}}$ by about $19 \%$, from 268 to $216 \mu \mathrm{m}$, and reduced the number density $\mathrm{n}_{\beta}$ from 0.27 to $0.16 \mathrm{~mm}^{-2}$. According to thermodynamic calculations (Table 2), the $\mathrm{Al}_{15} \mathrm{Si}_{2} \mathrm{Mn}_{4}$ phase starts to precipitate as the first phase at $661.1^{\circ} \mathrm{C}$, the $\alpha$-Al phase does this as the second at $610.9{ }^{\circ} \mathrm{C}$, the AlSi eutectics as the third at $560.2{ }^{\circ} \mathrm{C}$ and solidification ends at $522.6^{\circ} \mathrm{C}$. At $514.1^{\circ} \mathrm{C}, \mathrm{Al}_{2} \mathrm{Cu}$ starts to form. In the liquid alloy, Mn-rich precipitating as the first (Figures $10 \mathrm{~b}$ and 11) phase appears to have suitable conditions to grow and at $2 \mathrm{wt} . \%$ the Mn-rich average overall dimension is $\mathrm{L}_{\mathrm{Mn}} 268$ and $216 \mu \mathrm{m}$. Growth in the liquid alloy by forced convection is not conducive to an increase in the average overall dimension $\mathrm{L}_{\mathrm{Mn}}$, as can be seen from iron-rich intermetallics in the AlCu10Si10Fe1 and $\mathrm{AlCu} 4 \mathrm{Si6Fe} 2$ alloys studied. Forced flow caused a decrease in the average overall dimension $\mathrm{L}_{\mathrm{Mn}}$, and compared to AlCu4Si6Fe1, AlCu10Si10Fe1 and AlCu4Si6Mn0.65 alloys, the decisisve factor for the smaller phases should be the growth of Mn phases between $\alpha-\mathrm{Al}$ phases and the mechanical interaction. In the AlCu4Si6Mn2.0 alloy (Figure 11), the Mn phases precipitated first, but in AlCu4S6Mn0.65, they started after $\alpha$-Al, at $0.65 \mathrm{wt} . \%$ Fe the decrease under stirring is stronger $(-42 \%)$ than at 2 wt. $\% \mathrm{Mn}$, where $\mathrm{L}_{\mathrm{Mn}}$ decreased by $19 \%$, so the shortening seems to be determined by the forced flow occurring in the presence of $\alpha$-Al.

Flow reduced the secondary dendrite arm spacing in almost all alloys. Analyzing the parameters characterizing the microstructure (Table 1 ), the content of $\mathrm{Cu}$ element and the presence of $\mathrm{Al}_{2} \mathrm{Cu}$ phase, seem to have no effect on the microstructure modification under stirring. According to property diagrams and thermodynamic calculations, the $\mathrm{Al}_{2} \mathrm{Cu}$ phase precipitated after complete solidification, so $\mathrm{Al}_{2} \mathrm{Cu}$ in the liquid phase did not interact with other precipitated phases or with the liquid alloy. 
$\alpha-\mathrm{Al}$ grew as rosettes with decreasing $\mathrm{S}_{\mathrm{v}}$ in almost all of the alloys studied. Only for one alloy, AlCu10Si10Fe1, $S_{\mathrm{v}}$ increased, and in another alloy (AlCu4Si6Fe2.0), a non dendritic structure was observed by decreasing $S_{v}$. The specific surface $S_{v}$ is a valid parameter, very clearly signaling the presence of melt flow and its effect on the microstructure. Forced flow causes, with dendritic and non-dendritic structures, a decrease in $\mathrm{S}_{\mathrm{v}}$, and only for one alloy, an increase in $\mathrm{S}_{\mathrm{v}}$. An exception is the AlCu10Si10Fe1 alloy, where a high amount of eutectic phase occurred and the iron-rich phase precipitated first. This mechanism is unclear and requires further experimental and analytical investigations. Forced flow changed the specific surface $S_{\mathrm{v}}$ more strongly in simpler alloys, with a lower number of elements and occurring phases, so its signaling function is weaker in more complex alloys. The greatest modification of $\mathrm{S}_{\mathrm{v}}$ and also $\lambda_{2}$ occurred in $\mathrm{AlCu} 4$; the simplest alloy of those studied.

The present study confirmed the results of [63] for directional solidification of the AlSi5Fe1.0 alloy, where forced convection reduced average length $L_{\beta}$ of the $\beta$ phases by about $20 \%$ and increased the number density $n_{\beta}$ by about $17 \%$. The study also confirmed the results for equiaxed growth [59], where $\mathrm{L}_{\beta}$ also decreased by $20 \%$ and $\mathrm{n}_{\beta}$ increased by $47 \%$, in experiments performed by the same method and characterized by parameters [59] similar to those presented in Table 1 . The above-mentioned decrease in $\mathrm{L}_{\beta}$, also by the presence of $\mathrm{Al}_{2} \mathrm{Cu}$, is opposite to that in [59], where the presence of $\mathrm{Mg}_{2} \mathrm{Si}$ reduced changes in the microstructure presented by similar parameters $\mathrm{L}_{\beta}, \mathrm{n}_{\beta}$ and $\lambda_{2}$.

The conclusion is that the flow effect in equiaxed solidification, with a low temperature gradient and low cooling rate, caused an increase in the average length $L_{\beta}$ and a decrease in the number density $n_{\beta}$. Such an increase in $L_{\beta}$ was now observed in the alloys, where phase remelting was not possible and was contrary to the results in [63]. The importance of the increase in the liquid alloy can be seen in the AlCu10Si10Fe1.0 and AlCu4Si6Fe2.0 alloys, where longer phases were present at an iron content of $1 \%$ instead of $2 \%$, but with $\beta$ phases starting to precipitate much earlier than $\alpha$-Al. In the AlCu4Si6Fe2.0 alloy, about $29 \%$ Fe precipitates in fully liquid melt, whilst in the AlCu10Si10Fe1.0 alloy, it is $68 \%$ of $\beta$. This suggests a shortening of $\beta$ as an effect of mechanical fragmentation by the presence of $\alpha$-Al or other solid phases, whilst an increase in the length of $\beta$ as an effect of solute distribution changed under flow. In association with flow, the elimination of constitutional undercooling trough reduction of thermal and solutal diffusion layers at the solid-liquid interface needs more research and analysis. The fact that longer $\beta$ phases were observed in the AlCu10Si10Fe1.0 alloy than in the AlCu4Si6Fe2.0 alloy increases the importance of free growth in the liquid alloy in comparison to the iron concentration (1 or $2 \mathrm{wt} . \% \mathrm{Fe}$ ).

The analysis of Mn-containing alloys also supports the explanation that the shortening of $\beta$ is an effect of mechanical fragmentation through the presence of $\alpha-\mathrm{Al}$. For the AlCu4Si6Mn0.65 alloy, stirring reduced the average length $\mathrm{L}_{\mathrm{Mn}}$ by about $42 \%$ through the precipitation of Mn phases as a second phase, whilst in the AlCu4Si6Mn2.0 alloy, it decreased by about $19 \%$, where Mn-phases start to grow around $50{ }^{\circ} \mathrm{C}$ before $\alpha$-Al.

If Fe precipitates only between $\alpha-\mathrm{Al}$, there is a shortening of the $\beta$ phase, but when $\mathrm{Fe}$ phases can precipitate in completely liquid melt, then there is an increase in length. The increase in $\beta$ length is stronger owing to the higher amount of iron, so it is the iron content that is more important for $\beta$ length at flow than the temperature range before starting $\alpha-\mathrm{Al}$, between the temperature at which $\beta$ precipitation starts and the temperature at which $\alpha$-Al grows. In Mn-containing alloys, fluid flow causes an increase in the overall average dimension, both when the Mn-phase precipitates the first phase and also when it starts to grow as the second phase.

In Fe-containing alloys, fluid flow causes a decrease in the average length when the Fe phase starts to grow as the second phase; after the $\alpha$-Al phase, while there is an increase, this is only when the Fe-phase precipitates first. However, it should be mentioned that precipitation of both $\mathrm{Al}_{8} \mathrm{Fe}_{2} \mathrm{Si}$ and $\mathrm{Al}_{9} \mathrm{Fe}_{2} \mathrm{Si}_{2}$ phases occurred in the alloy. 


\section{Conclusions}

1. The forced convection generated by electric coils led to the formation of rosettes with smaller dendrites instead of equiaxed dendrites, as an effect of the rotation of the dendrite tip and ripened arms of the deformed dendrites. Precipitating minor spheroids were found as part of deformed dendritic crystals.

2. Stirring shortened the solidification time and secondary dendrite arm spacing $\lambda_{2}$ for almost all alloys. The exponents in the formula for $\lambda_{2}$ calculations should take different values from those determined in previous research.

3. For almost all the studied alloys, $\mathrm{S}_{\mathrm{V}}$ decreased (in the range between $-23 \%$ and $-41 \%$ ) under fluid flow, which means that the dendrites or rosettes are more oval and larger under the influence of stirring. The calculation of $S_{v}$ based on solidification time requires an accurate coefficient.

4. Forced convection causes a decrease in the length of $\beta-\mathrm{Al}_{5} \mathrm{FeSi}$ and an increase in the number density in alloys, where $\beta$ platelets precipitate after other phases (e.g $\alpha-\mathrm{Al})$. What is completely new is that, in the alloys where iron-rich phases precipitate first and grow initially alone in the liquid alloy, melt stirring causes an increase in length and a decrease in number density.

5. Melt stirring causes a decrease in the length of Mn-rich phases and an increase in the number density in all the studied alloys, both in alloys where Mn-phases form as the first precipitates and also when they grow as second or third precipitates.

6. Melt flow changed the eutectic spacing $\lambda_{\mathrm{E}}$ depending on the alloy composition. In Fe-containing alloys, an increase was noticed, while in Mn-containing alloys, $\lambda_{\mathrm{E}}$ decreased. The presence of $\mathrm{Mn}$ in the alloy increased $\lambda_{\mathrm{Al} 2 \mathrm{Cu}}$ only weakly.

7. For all the studied alloys it was found, that forced convection appears to have no effect on the spacing of $\mathrm{Al}_{2} \mathrm{Cu}$ eutectics precipitating below the solidus temperature, and vice versa, $\mathrm{Al}_{2} \mathrm{Cu}$ does not determine fluid flow and phases occurring during solidification processes.

8. There was a decrease in the length of $\beta-\mathrm{Al}_{5} \mathrm{FeSi}$ and $\mathrm{Mn}$-phases caused by stirring occurred in equiaxed solidification without remelting, probably through mechanical fragmentation, modified solute distribution and additional nucleation sites. The increase in the $\beta$ platelet length due to solidification in fully liquid alloys probably results from modified solute distribution and lack of obstacles.

9. The application of electromagnetically induced melt flow and the efficiency in microstructure modification depends on the phase growth sequence, the precipitating phases, and the chemical composition of the alloys.

Funding: The research leading to these results has received funding from the People Programme (Marie Curie Actions) of the European Union's Seventh Framework Programme (FP7/2007-2013) under the REA grant agreement $\mathrm{n}^{\circ}$ PCIG13-GA-2013-613906. More information on the funded projects is available at: www.iFlowFePhase.info (accessed on 29 August 2021).

Data Availability Statement: The data presented in this study are available on request from the corresponding author.

Conflicts of Interest: The funding sponsor is the European Union's Seventh Framework Programme (FP7/2007-2013). The funding sponsors had no role in the design of the study; in the collection, analyses, or interpretation of data, in the writing of the manuscript, and in the decision to publish the results.

\section{References}

1. Mondolfo, L.F. Aluminium Alloys: Structure and Properties; Butterworths \& Co.: London, UK, 1976.

2. Glazoff, M.V.; Zolotorevsky, V.S.; Belov, N.A. Casting Aluminum Alloys; Elsevier Science Pub Co.: Amsterdam, The Netherlands, 2007; ISBN 13:978-0080453705. [CrossRef]

3. Nong, G. (Ed.) Aluminum Alloys; MDPI: Basel, Switzerland, 2018.

4. Flemings, M. Behavior of metal alloys in the semisolid state. Metall. Mat. Trans. B 1991, 22B, 269-293. [CrossRef] 
5. Pola, A.; Tocci, M.; Kapranos, P. Microstructure and Properties of Semi-Solid Aluminum Alloys: A Literature Review. Metals 2018, 8, 181. [CrossRef]

6. Modigell, M.; Pola, A.; Tocci, M. Rheological Characterization of Semi-Solid Metals: A Review. Metals 2018, 8, 245. [CrossRef]

7. Li, Y.; Zhou, R.; Li, L.; Xiao, H.; Jiang, Y. Microstructure and Properties of Semi-solid ZCuSn10P1 Alloy Processed with an Enclosed Cooling Slope Channel. Metals 2018, 8, 275. [CrossRef]

8. Jiang, J.; Xiao, G.; Che, C.; Wang, Y. Microstructure, Mechanical Properties and Wear Behavior of the Rheoformed 2024 Aluminum Matrix Composite Component Reinforced by Al2O Nanoparticles. Metals 2018, 8, 460. [CrossRef]

9. Beil, W.L.; Brollo, G.L.; Zoqui, E.J. A Continuous Casting Device with Electromagnetic Stirring for Production of SSM Feedstock Using Al-Si Alloys. Mat. Res. 2021, 24, 3. [CrossRef]

10. Brollo, G.L.; Proni, C.T.W.; Zoqui, E.J. Thixoforming of an Fe-Rich Al-Si-Cu Alloy-Thermodynamic Characterization, Microstructural Evolution, and Rheological Behavior. Metals 2018, 8, 332. [CrossRef]

11. Eslami, M.; Payandeh, M.; Deflorian, F.; Jarfors, A.E.W.; Zanella, C. Effect of Segregation and Surface Condition on Corrosion of Rheo-HPDC Al-Si Alloys. Metals 2018, 8, 209. [CrossRef]

12. Mohammed, M.N.; Omar, M.Z.; Al-Zubaidi, S.; Alhawari, K.S.; Abdelgnei, M.A. Microstructure and Mechanical Properties of Thixowelded AISI D2 Tool Steel. Metals 2018, 8, 316. [CrossRef]

13. Nafisi, S.; Ghomashchi, R. Semi-Solid Processing of Aluminum Alloys; Springer: Berlin, Germany, 2016.

14. Wang, H.; Davidson, C.J.; St. John, D.H. Semisolid microstructural evolution of AlSi7Mg during partial remelting. Mater. Sci. Eng. A 2004, 368, 159-167. [CrossRef]

15. Pacheco, M.G. Electromagnetic Processing of Molten Light Alloys Reinforced by Micro/Nanoparticles. Ph.D. Thesis, Universite Grenoble Alpes UGA, Grenoble, France, 13 March 2017.

16. Das, A.; Ji, S.; Fan, Z. Solidification microstructures obtained by a novel twin screw liquidus casting method. In Proceedings of the 7th International Conference on Demi-Solid Processing of Alloys and Composites, Tsukuba, Japan, 25-27 September 2002; pp. 689-694.

17. Li, M.; Murakami, Y.; Matsui, I.; Omura, N.; Tada, S. Imposition Time Dependent Microstructure Formation in 7150 Aluminum Alloy Solidified by an Electromagnetic Stirring Technique. Mater. Trans. 2018, 59, 1603-1609. [CrossRef]

18. He, M.; Zhang, Z.; Mao, W.; Li, B.; Bai, Y.; Xu, J. Numerical and Experimental Study on Melt Treatment for Large-Volume 7075 Alloy by a Modified Annular Electromagnetic Stirring. Materials 2019, 12, 820. [CrossRef] [PubMed]

19. Jin, C.K. Microstructure of Semi-Solid Billets Produced by Electromagnetic Stirring and Behavior of Primary Particles during the Indirect Forming Process. Metals 2018, 8, 271. [CrossRef]

20. Nakato, H.; Oka, M.; Itoyama, S.; Urata, M.; Kawasaki, T.; Hashiguchi, K.; Okano, S. Continous Semi-Solid Casting Process for Aluminum Alloy Billets. Mater. Trans. 2002, 43, 24-29. [CrossRef]

21. Ferreira, A.F.; Castro, J.A.; Ferreira, L.O. Predicting Secondary-Dendrite Arm Spacing of the Al-4.5wt $\%$ Cu Alloy During Unidirectional Solidification. Mater. Res. 2017, 20, 68-75. [CrossRef]

22. Barros, A.S.; Mahno, I.A.; Souza, F.A.; Mota, C.A.; Moreira, A.L.; Silva, M.A.; Rocha, O.L. Measurements of Microhardness During Transient Horizontal Directional Solidification of Al-Rich Al-Cu Alloys: Effect of Thermal Parameters, Primary Dendrite Arm Spacing and Al2Cu Intermetallic Phase. Met. Mater. Int. 2015, 21, 429-439. [CrossRef]

23. Lei, Q.; Wang, J.; Misra, A. Mechanical Behavior of Al-Al2Cu-Si and Al-Al2Cu Eutectic Alloys. Crystals 2021, 11, 194. [CrossRef]

24. Belov, N.A.; Aksenov, A.A.; Eskin, D.G. Iron in Aluminium Alloys-Impurity and Alloying Element, 1st ed.; Taylor and Francis Group: London, UK, 2002. [CrossRef]

25. Shabestari, S.G. The effect of iron and manganese on the formation of intermetallic compounds in aluminum-silicon alloys. Mater Sci. Eng. 2004, 383, 289-298. [CrossRef]

26. Thermo-Calc 4.1-Software package from Thermo-Calc Software AB. Stockholm, Sweden. Available online: www.thermocalc.se (accessed on 4 August 2021).

27. Niroumand, B.; Xia, K. 3D study of the structure of primary crystals in a rheocast Al-Cu alloy. Mater. Sci. Eng. 2000, 283, 70-75. [CrossRef]

28. Birol, Y. A357 thixoforming feedstock produced by cooling slope casting. J. Mater. Process. Technol. 2007, 186, 94-101. [CrossRef]

29. Mullis, A. Growth induced dendritic bending and rosette formation during solidification in a shearing flow. Acta Mater. 1999, 47, 1783-1789. [CrossRef]

30. Ji, S.; Fan, Z.; Bevis, M.J. Semi-solid processing of engineering alloys by a twin-screw rheomoulding process. Mater. Sci. Eng. 2001, 299, 210-217. [CrossRef]

31. Das, A.; Ji, S.; Fan, Z. Morphological development of solidification structures under forced fluid flow: A Monte Carlo simulation. Acta Mater. 2002, 50, 4571-4585. [CrossRef]

32. Birol, Y. Evolution of globular microstructures during processing of aluminum slurries. Trans. Nonferrous Met. Soc. China 2013, 23 , 1-6. [CrossRef]

33. Li, T.; Lin, X.; Huang, W. Morphological evolution during solidification under stirring. Acta Mater. 2006, 54, 4815-4824. [CrossRef]

34. Martinez., R.A.; Flemings, M.C. Evolution of particle morphology in semisolid processing. Met. Mat. Trans. A. 2005, 36, 2205-2210. [CrossRef]

35. Kurz, W.D. Fisher. In Fundamentals of Solidification; Trans Tech Public: Bäch, Switzerland, 1992; pp. 85-90.

36. Dantzig, J.A.; Rappaz, M. Solidification; EPFL Press: Lausanne, Switzerland, 2009; ISBN 9780849382383. 
37. Stefanescu, D. Science and Engineering of Casting and Solidification; Springer: Boston, MA, USA, 2009; ISBN 978-0-387-74609-8. [CrossRef]

38. Wang, C.Y.; Beckermann, C. Equiaxed Dendritic Solidification with Convection: Part II. Numerical Simulations for an Al-4 Wt Pct Cu Alloy. Metall. Mater. Trans. A 1996, 27A, 2765. [CrossRef]

39. Mendoza, R.; Alkemper, J.; Voorhees, P. The morphological evolution of dendritic microstructures during coarsening. Metall. Mater. Trans. A 2003, 34, 481-489. [CrossRef]

40. Hunt, J.D. Pattern formation in solidification. Sci. Technol. Adv. Mater. 2001, 2, 147-155. [CrossRef]

41. Hunt, J.D.; Lu, S.Z. Numerical modeling of cellular/dendritic array growth: Spacing and structure predictions. Metall. Mater. Trans. A 1996, 27, 611-623. [CrossRef]

42. Kattamis, T.Z.; Flemings, M.C. Dendrite morphology. Microsegregation and Homogenization of low alloy steel. Trans. Met. Soc. AIME 1965, 233, 992-999.

43. Rappaz, M.; Boettinger, W. On dendritic solidification of multicomponent alloys with unequal liquid diffusion coefficients. Acta Mater. 1999, 47, 3205-3219. [CrossRef]

44. Steinbach, S.; Ratke, L. The influence of fluid flow on the microstructure of directionally solidified AlSi-base alloys. Metall. Mater. Trans. A 2007, 38, 1388-1394. [CrossRef]

45. Mortensen, A. On the rate of dendrite arm coarsening. Metall. Mater. Trans. A 1991, 22, 569-574. [CrossRef]

46. Voorhees, P.W.; Glicksman, M.E. Ostwald ripening during liquid phase sintering-Effect of volume fraction on coarsening kinetics. Metall. Mater. Trans. A 1984, 15, 1081-1089. [CrossRef]

47. Bouchard, D.; Kirkaldy, J.S. Prediction of dendrite arm spacing in unsteady- and steady-state heat flow. Metall. Mater. Trans. B 1997, 28, 651-663. [CrossRef]

48. Bellon, B.; Boukellal, A.K.; Isensee, T.; Wellborn, O.M.; Trumble, K.P.; Krane, M.J.M.; Titus, M.S.; Tourret, D.; Llorca, J. Multiscale prediction of microstructure length scale in metallic alloy casting. Acta Mater. 2021, 207, 116686. [CrossRef]

49. Mullis, A.M. The effects of fluid flow on the secondary arm coarsening during dendritic solidification. J. Mater. Sci. 2003, 38, 2517-2523. [CrossRef]

50. Diepers, H.J.; Beckerman, C.; Steinbach, I. Simulation of convection and ripening in a binary alloy mush using the phase field method. Acta Mater. 1999, 47, 3663-3678. [CrossRef]

51. Kasperovich, G.; Genau, A.; Ratke, L. Mushy zone coarsening in an AlCu30 alloy accelerated by a rotating magnetic field. Metall. Mater. Trans. A 2011, 42, 1657-1666. [CrossRef]

52. Ratke, L.; Thieringer, W.K. The influence of particle motion on Ostwald ripening in liquids. Acta Mater. 1985, 33, 1793-1802. [CrossRef]

53. Marsh, S.P.; Glicksman, M.E. Overview of geometric effects on coarsening of mushy zones. Metall. Mater. Trans. A 1996, 27, 557-567. [CrossRef]

54. Loué, W.R.; Suéry, M. Microstructural evolution during partial remelting of AlSi7Mg alloys. Mater. Sci. Eng. A 1995, 203, 1-13. [CrossRef]

55. Jackson, K.A.; Hunt, J.D. Lamellar and rod eutectic growth. Trans. AIME 1966, 236, 1129-1142.

56. Sous, S. Instationäre Erstarrung Eutektischer Al-Si Legierungen. Ph.D. Thesis, RWTH, Aachen, Germany, 2000.

57. Mikolajczak, P.; Ratke, L. Intermetallic phases and microstructure in AlSi alloys influenced by fluid flow. Miner. Met. Soc. TMS 2011, 10, 9781118062173. [CrossRef]

58. Mikolajczak, P.; Ratke, L. Thermodynamic assessment of mushy zone in directional solidification. Arch. Foundry Eng. 2015, 15, 101-109. [CrossRef]

59. Mikolajczak, P. Microstructural Evolution in AlMgSi Alloys during Solidification under Electromagnetic Stirring. Metals 2017, 7, 89. [CrossRef]

60. Nafisi, S.; Emad, D.; Shehata, T.; Ghomashchi, R. Effects of electromagnetic stirring and superheat on the microstructural characteristics of Al-Si-Fe alloy. Mater. Sci. Eng. A 2006, 432, 71-83. [CrossRef]

61. Fang, X.; Shao, G.; Liu, Y.Q.; Fan, Z. Effects of intensive forced melt convection on the mechanical properties of Fe containing Al-Si based alloys. Mater. Sci. Eng. A 2007, 445-446, 65-72. [CrossRef]

62. Steinbach, S.; Euskirchen, N.; Witusiewicz, V.; Sturz, L.; Ratke, L. Fluid flow effects on intermetallic phases in Al-cast alloys. Trans. Indian Inst. Met. 2007, 60, 137-141. [CrossRef]

63. Mikolajczak, P.; Ratke, L. Effect of stirring induced by rotating magnetic field on $\beta-\mathrm{Al}_{5} \mathrm{FeSi}$ intermetallic phases during directional solidification in AlSi alloys. Int. J. Cast Met. Res. 2013, 26, 339-353. [CrossRef] 